\title{
KEY MANAGEMENT ISSUES FOR LOW-VOLUME RURAL ROADS IN ASIA AND THE PACIFIC
}

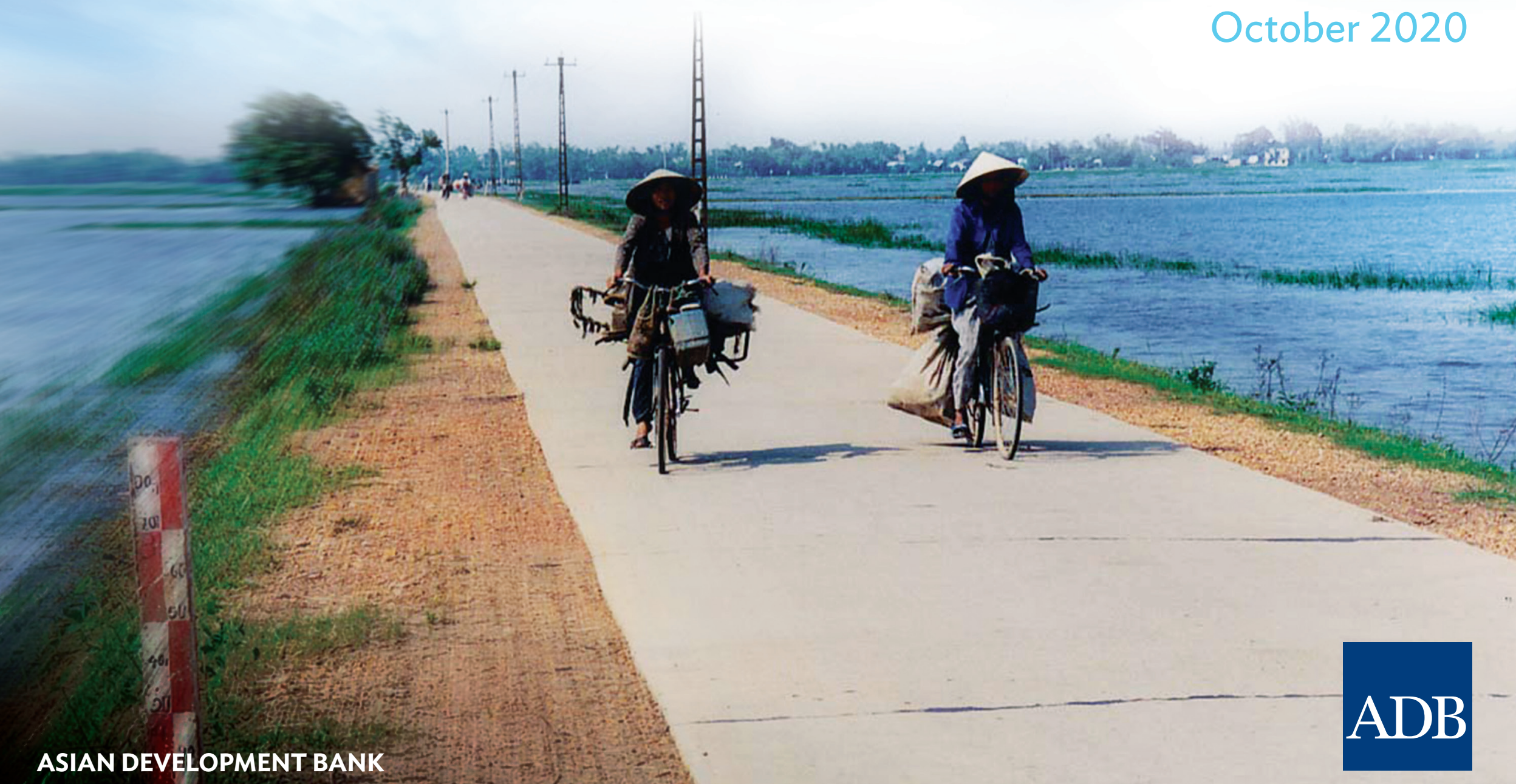




\section{KEY MANAGEMENT ISSUES FOR LOW-VOLUME RURAL ROADS IN ASIA AND THE PACIFIC}

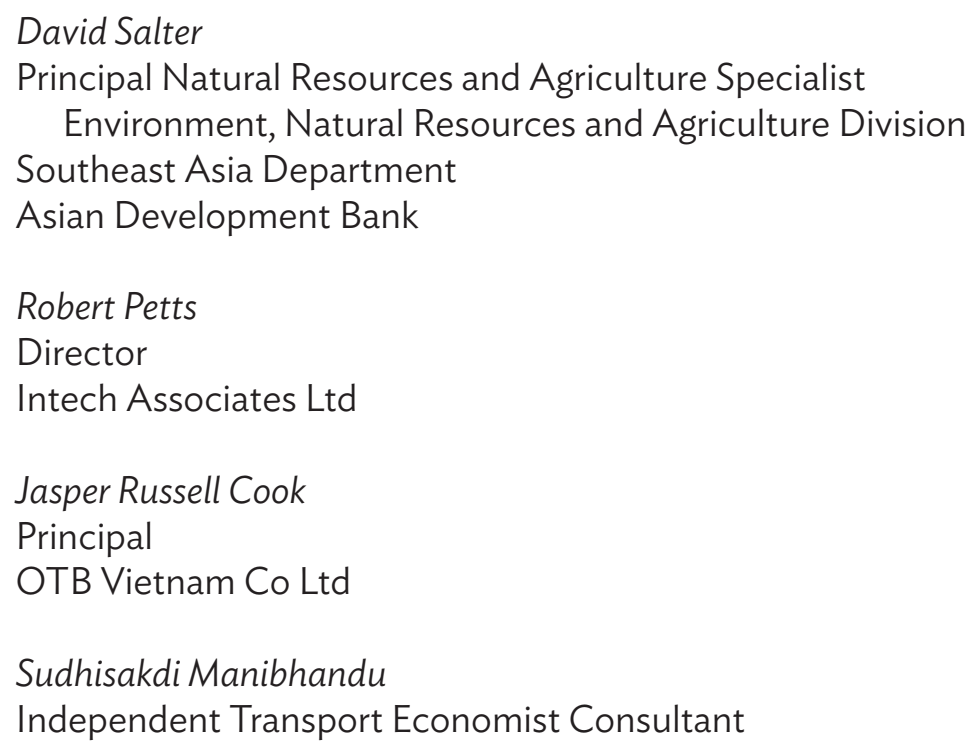


(C) 2020 Asian Development Bank

6 ADB Avenue, Mandaluyong City, 1550 Metro Manila, Philippines

Tel +6328632 4444; Fax +63286362444

www.adb.org

All rights reserved. Published in 2020.

ISBN 978-92-9262-371-5 (print), 978-92-9262-372-2 (electronic), 978-92-9262-373-9 (ebook)

Publication Stock No. ARM200211

DOI: http://dx.doi.org/10.22617/ARM200211

The views expressed in this publication are those of the authors and do not necessarily reflect the views and policies of the Asian Development Bank (ADB) or its Board of Governors or the governments they represent.

ADB does not guarantee the accuracy of the data included in this publication and accepts no responsibility for any consequence of their use. The mention of specific companies or products of manufacturers does not imply that they are endorsed or recommended by ADB

in preference to others of a similar nature that are not mentioned.

By making any designation of or reference to a particular territory or geographic area, or by using the term "country" in this document, ADB does not intend to make any judgments as to the legal or other status of any territory or area.

ADB encourages printing or copying information exclusively for personal, educational, and noncommercial use with proper acknowledgment of ADB. Users are restricted from reselling, redistributing, or creating derivative works for commercial purposes without the express, written consent of ADB. Please contact pubsmarketing@adb.org if you have questions or comments with respect to content, or if you wish to obtain copyright permission.

Corrigenda to ADB publications may be found at http://www.adb.org/publications/corrigenda.

Note:

ADB recognizes "Vietnam" as Viet Nam.

On the cover: Assured rural access underpins social economic integration of rural areas into the drivers of development and provides the ensuing benefits to the broadest range of rural people (photo by Robert Petts) 


\section{Contents}

Tables and Figures $\quad$ iv

I. Introduction

Purpose

Low-Volume Rural Roads and Sustainable Development Goals

Low-Volume Rural Roads as Integral to the Transport Network

II. Strategic Challenges

III. Strategic Issues

Policy Framework Driving Low-Volume Rural Road Network Strategy

Low-Volume Rural Road Environment and Its Impacts

Challenges Specific to Low-Volume Rural Roads

Classification and Appropriate Standards

Climate Impact

Research Uptake and Application

Capacity Building

IV. Implementation

Strategic Decisions in Response to the Road Environment

Local Material Use

Fit-for-Purpose Design

Whole Life Costing

Appropriate Technology

Road Safety

Quality Management

Road Asset Preservation 


\section{Tables and Figures}

\section{Tables}

1 Key Characteristics of Low-Volume Rural Roads 4

2 Sustainability Framework and Issues 8

3 Typical Generic Road Network Classification 10

4 Climate Change Impacts on Transport Infrastructure 12

5 Possible Performance Levels 14

6 Steps to Embed Research Capacity 16

7 Surfacing and Paving Options 22

8 Considerations in Selecting Economic Analysis Models 25

9 Quality Control Procedures in the Rural Road Sector 28

10 Technical Audit Phases 29

11 Low-Volume Rural Road Maintenance Activity Assessment 30

12 Low-Volume Rural Roads in Relation to the ADB Strategy 2030

\section{Figures}

1 Relative Impact of Traffic and Other Road Environmental Factors 3

2 Road Environment, Natural, and Related Factors 7

3 Interlinked Road Asset Deterioration Impact Factors

4 Strategic Options for Climate Resilience 13

5 Decision Flowchart for Natural Gravel as a Rural Road Surface Option 20

6 Two-State Identification of the Most Appropriate Surfacing and Paving Options 23 


\section{INTRODUCTION}

\section{Purpose}

This awareness-raising material aims to help address key management issues in implementing successful low-volume rural roads (LVRRs) programs, bearing in mind the broader strategic network and connectivity requirements. It describes the

(i) importance of LVRRs;

(ii) key management issues including policy, classification, design, sustainability, climate change impacts, development strategies, technology choices, safety, economic analysis, and knowledge development; and

(iii) relevance of LVRR to Strategy 2030 of the Asian Development Bank (ADB). It will enable ADB to engage with developing member countries (DMCs) that wish to improve portions of their LVRRs in an informed and comprehensive manner.

Well-developed and well-managed LVRRs are essential for

(i) integrating and improving efficiency of the overall transport network,

(ii) integrating rural populations into national social and development programs,

(iii) market-oriented agricultural development and food security,

(iv) rural enterprise development,

(v) achieving more than half of the Sustainable Development Goals (SDGs), and

(vi) achieving ADB's Strategy 2030 operational priority 5 "promoting rural development and food security" as well as contributing to several other operational priorities.

\section{Low-Volume Rural Roads and Sustainable Development Goals}

Rural transport plays an indispensable role in achieving more than half of the SDGs and fulfilling the promise of the 2030 Agenda for Sustainable Development to "leave no one behind." Although there is no dedicated SDG target on rural access, there are numerous linkages between rural access and the SDGs. Successful scaled-up implementation of rural transport will contribute to realizing

(i) SDG 1 to alleviate poverty,

(ii) SDG 2 to achieve zero hunger and ensure food security,

(iii) SDG 3 to ensure health and well-being,

(iv) SDG 4 to provide access to education,

(v) SDG 5 to empower women in rural areas,

(vi) SDG 6 to facilitate access to clean water and sanitation,

(vii) SDG 8 to promote inclusive growth and economic opportunities,

(viii) SDGs 9 and 11 to contribute to sustainable infrastructure and communities for all, and

(ix) SDG 13 to increase climate resilience and adaptation in rural areas.

In addition, there is a direct linkage to rural access in SDG indicator 9.1.1 (proportion of the rural population who live within 2 kilometers [km] of an all-season road) (Cook et al. 2017). Rural transport is key to rural economic growth and poverty reduction. Without effective transport, rural communities are isolated from markets, employment opportunities, health care, and education. 
A lack of access to basic services and markets is recognized to be a major constraint on development and an important contributor to poverty. It is estimated that $58 \%$ of the population in developing countries, $78 \%$ of the extreme poor (Olinto et al. 2013), and $85 \%$ of the multidimensional poor (Alkire et al. 2014) are located in rural areas (Hine et al. 2019).

\section{Low-Volume Rural Roads as Integral to the Transport Network}

LVRRs are an integral part of a country's surface transport network, providing essential connectivity to support and sustain socioeconomic development in ADB's DMCs. Other elements of the transport network are high-volume roads (HVRs); urban roads; and rail, river, and coastal transport modes. LVRRs have particularly strong links to urban road networks and HVRs traversing rural areas.

Although the transport network is seen as a single entity or seamless continuum from an end user viewpoint, significant differences exist between the various transport modes from the network management and supply-side perspective, with specific challenges to overcome. 
Recognizing and overcoming the challenges at a strategic level is an essential element of effective LVRR management. Challenges may be one or more of the following:

- Separate road authorities. Central and rural road authorities involve different budgets and administrations, such as in Cambodia and Myanmar.

- One road authority. LVRRs may receive a lower priority profile within the central management like in the Lao People's Democratic Republic and Viet Nam.

- Road design and construction. Management is constrained by competing budgets based on various design and construction needs.

- Lack of road standards and specifications. Locally appropriate and efficient standards and specifications must be set.

- Local road constraints. Technical capacity constraints differ in each country and area.

- Differing viewpoints. LVRRs are often seen as the last mile by the central authority but are considered the first mile by the rural authority.'

To be sustainably effective, LVRRs cannot be designed, constructed, and maintained using the approaches appropriate to HVRs. Below a cutoff point of around 200-300 equivalent motorized vehicles per day (depending on the physical environment), the design challenges change in response to the increasing influence of road environment factors relative to traffic and, as demonstrated in this paper, continue to change down to LVRRs.

\footnotetext{
The term "last mile" in a road network is considered the end section of the network by the national level road authorities and is usually thought of as having low importance compared to the higher levels of the road system hierarchy. In contrast, the same section has much more importance to the local rural road authorities and is often referred to as the "first mile" of the road network.
}

\section{Figure 1: Relative Impact of Traffic and Other Road} Environmental Factors

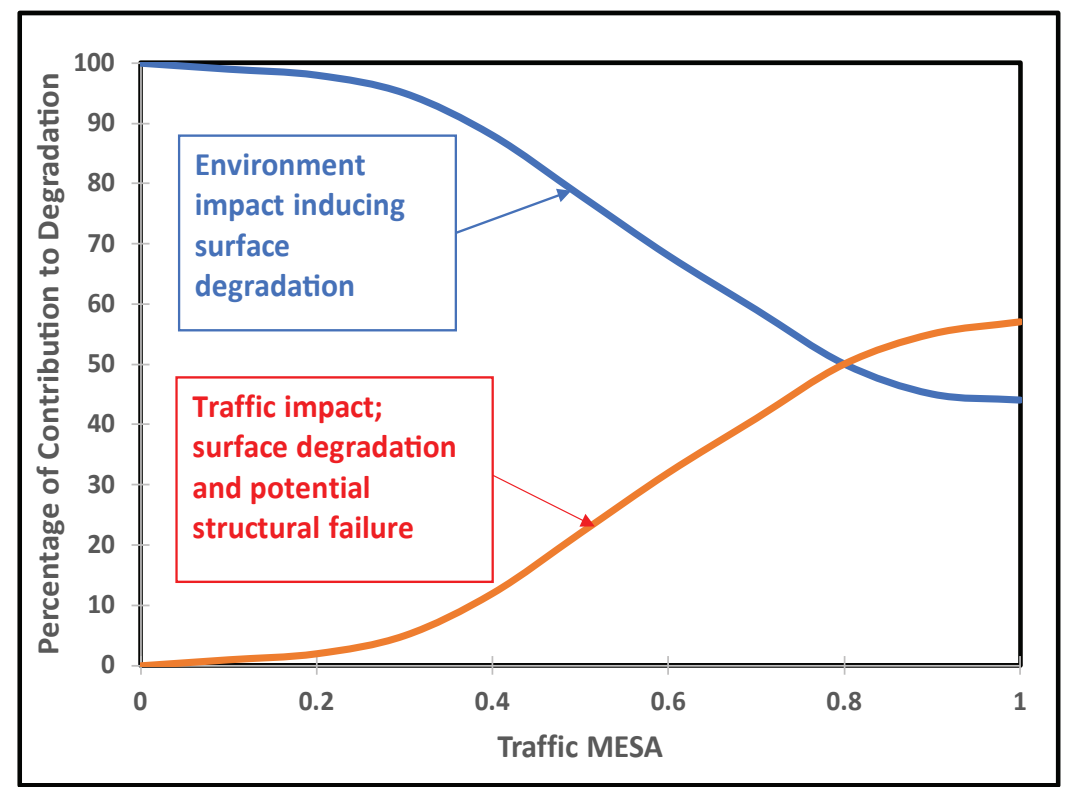

MESA = million equivalent standard axles (equal to a loading of 80 kilonewton).

Source: ReCAP. 2020. Low Volume Rural Road Design Manual, Ministry of Construction, Republic of the Union of Myanmar Department of Rural Road Development.

There is an upper limit to roads that may be included within the definition of LVRR. Roads within the LVRR definition require a change in approach to their design and construction. From an engineering viewpoint, the inclusion in the LVRR definition is normally taken when traffic volume is not the dominant factor influencing road deterioration 
but the environment around the road. The LVRR definition is commonly taken to be applicable for traffic of up to about 0.8-1 million equivalent standard axles (ESA) during the design life of the road pavement. (ReCAP 2020).

There are significant differences in the approach to designing LVRRs and particularly those with very light traffic. Very low trafficked roads can be designed with an emphasis on surface erosion prevention rather than base or subgrade failure, thus providing a significant saving in pavement costs. There are provisions in this approach in terms of low axle loads and specific site conditions. The approach still firmly follows the general principles of good practice road design - the roads should be fit-for-purpose and meet key transport targets (Cook, Petts, and Rolt 2013).

Understanding the significance of the calculation and range of axle loads is important where this relationship is valid. For very high-axle loads supporting a vehicle that may pass a rural road a few times a month only, the control for road design may need to be based on tire pressure. Traffic surveys are crucial to understanding the purpose of any road. Figure 1 outlines the general impacts of traffic and the environment on an LVRR.

Table 1 provides LVRR characteristics and issues.

\section{Table 1: Key Characteristics of Low-Volume Rural Roads}

\section{Characteristics}

Task-based

Environmentally compatible and safety

Local resource-based

Affordable

\section{Description}

LVRRs should suit the road function and its traffic (people and vehicles).

LVRRs need to be compatible with (i) the local road sector characteristics, (ii) the engineers and technicians who will design the roads, (iii) the contractors and laborers who will construct them, (iv) the people who will maintain them, and (v) the available construction materials.

LVRRs should be suitable for and, if necessary, adapted to the local road environment impact factors. Road safety considerations need to be integrated into the design.

The engineers and technicians who facilitate the construction of LVRRs and associated structures must use estimates of the whole life asset costs that will not exhaust budgets or place excessive maintenance burdens on local communities.

LVRR = low-volume rural road.

Source: R. Petts, J. Cook, and D. Salter. 2008. Key Management Issues for Low Volume Rural Roads in Developing Countries. Paper for INCOTALS 2008: South Asia Moves Forward.

Colombo. 28 July. 


\section{Policy Framework Driving Low-Volume Rural Road Network Strategy}

The road network is usually the most valuable national public asset, yet it rarely receives the level of professional asset management approach its importance deserves. It is essential that an appropriate national transport sector policy framework exists for the investment in and the management of all roads, including LVRRs (Petts, Cook, and Salter 2008). This enhances coherence and consistency leading to improved overall cost efficiency and performance of the transport network. An LVRR-focused policy derived from national development and national transport policies acts as a necessary driver of rural transport strategy (Southern African Development Community 2003).

The policy framework should include aspects of

- the role of the LVRR network and performance and service level objectives;

- the legal status and ownership of LVRRs;

- classification or categorization of the road infrastructure assets;

- quantification, condition, and prioritization of the assets;

- allocation of responsibilities for managing the assets, including government, community, private sector, and other stakeholder roles;

- financingarrangementsfor road improvements and maintenance;

- application of appropriate technology and optimal use of available local resources;

- $\quad$ setting and monitoring standards and specifications;
- planning and prioritizing asset preservation and maintenance over construction works;

- efficiently implementing maintenance and construction works;

- enhancing overall transport connectivity and strengthening the links within the road hierarchy;

- interface with inland water transport and other transport modes;

- sector human resource and sector capacity development;

- social, gender, and vulnerable group issues;

- environmental, climate resilience, and sustainability issues;

- road safety and health engagement issues;

- road use and traffic restriction (including loading) issues; and

- monitoring of performance of public assets and investments (Petts, Cook, and Salter 2008).

It is also useful to look at rural access improvement as an evolving, sequential, longer-term process linked to DMC economic achievement and gross domestic product growth. Initially, providing basic access or motorcycle trails enables people to expand their economic activities and increase their incomes. This leads to higher traffic levels, and eventually to a need to further improve transport quality and efficiency, which may initially justify upgrading to LVRR and, if this process continues, may eventually justify high-volume rural road (HVRR). The process perspective has several advantages. Basic access becomes an initial priority, supporting an equitable, fast-track approach to achieving universal basic access. The risk of investing prematurely in more costly types of infrastructure is mitigated. Also, once investment in LVRR or HVRR becomes justified, the local economy has expanded, so more resources are available for meeting the costs of future maintenance (Sustainable Mobility for All 2019). 


\section{Low-Volume Rural Road Environment and Its Impacts}

The principal elements in the road design process are traditionally based on traffic loading and road base, sub-base, and subgrade strengths. In the case of LVRRs, this traditional approach requires some modifications. It is now appreciated that additional road environment factors must be considered if the designs are to be costeffective and sustainable. The performance of an LVRR depends on a whole range of factors that cumulatively can be described as the 'road environment.' The design engineer needs to understand how all these factors impact LVRR. Factors important to the road environment can be broadly grouped as

(i) environment factors-largely uncontrollable,

(ii) road task,

(iii) operational environment-largely controllable, and

(iv) local resources-largely uncontrollable but with some modifications (Petts, Cook, and Salter 2008).

These factors are illustrated in Figure 2.

\section{Challenges Specific to Low-Volume Rural Roads}

Often, a substantial proportion of the LVRR network is developed only to an earth or a gravel surface standard (Petts, Cook, and Salter 2008). Individual routes are often in poor condition and sometimes severed during heavy rains, causing high transport costs and unreliable access. Upgrading, rehabilitating, or maintaining LVRRs to a fit-for-purpose condition presents a range of challenges and decisions to be made within the road environment, the overall context of sustainable connectivity of the transport network as a whole, and the economic framework.

Key early decisions on the planning of rural road improvement program revolve around the following issues:

- accurate current and future needs that the program is being implemented to satisfy;

- connectivity linkages with other transport modes, and network isolation and redundancy; ${ }^{2}$

- economic timescale in which the program operates, impacting on whole life costing (WLC) and design life;

- level of intervention as well as upgrade, rehabilitation, maintenance, or spot improvement; and

- required level of performance-e.g., all-weather, all-season, or seasonal-leading to preliminary ideas on "sealing" or "nosealing" interventions. ${ }^{3}$

Sustainability is a crucial concept in program planning. In addition to ensuring that the design developed is technically appropriate and is within the financial envelope, the project manager needs to consider other factors that could influence the success of the LVRR design approach, its implementation, and its long-term sustainability (Véron-Okamoto and Sakamoto 2014). Table 2 presents key sustainability issues.

In this context, redundancy refers to the provision of multiple or overlapping access, either by roads or a combination of, for example, road and river transport.

3 The sealing of a road refers to the application of a surface treatment that prevents the entrance of water into the road, usually achieved with bituminous or concrete surfaces. An unsealed road usually has a surface of unbound gravel or earth. 
Figure 2: Road Environment, Natural, and Related Factors

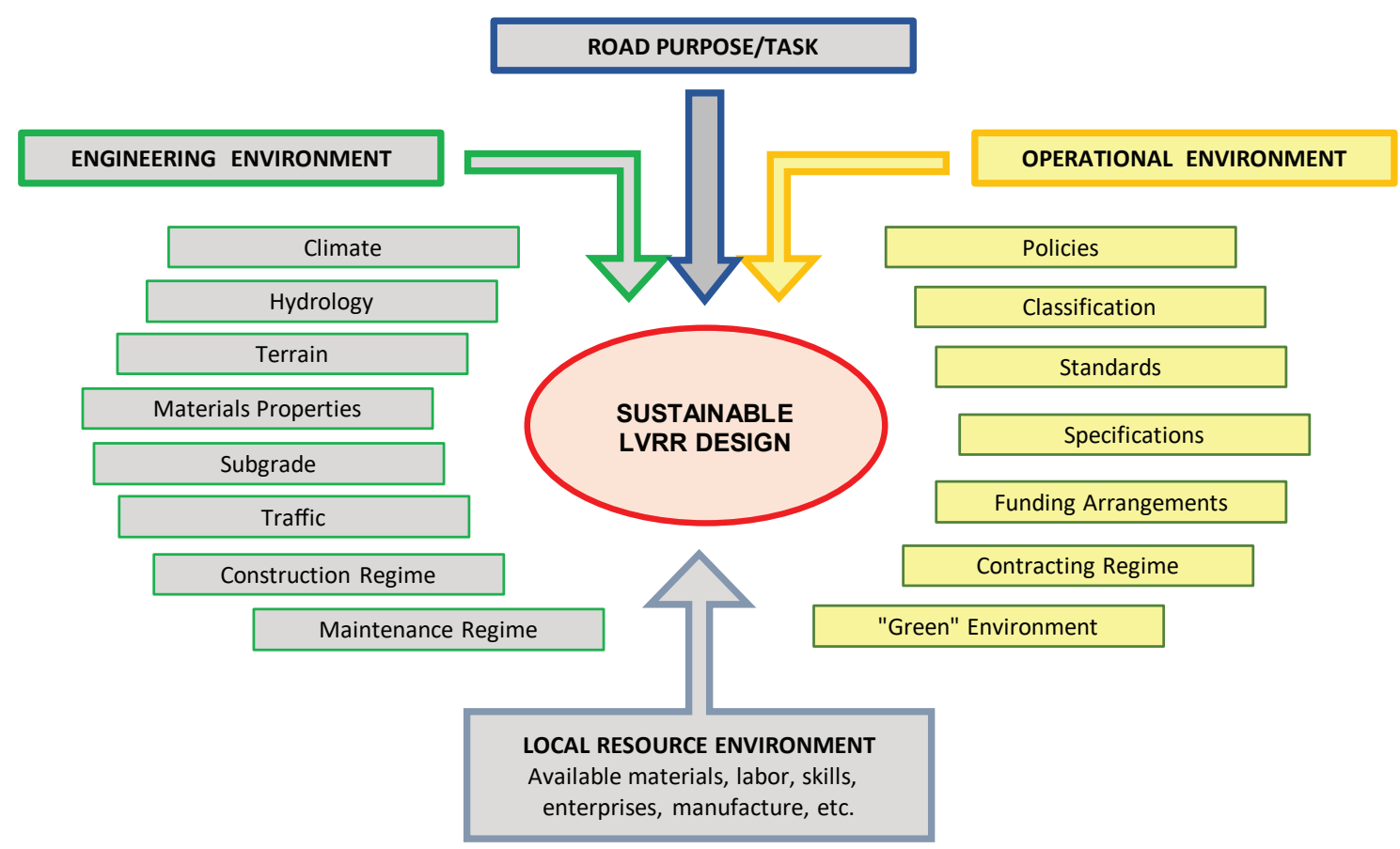

LVRR = low-volume rural road.

Source: J. R. Cook, R. C. Petts, and J. Rolt 2013. Low Volume Rural Road Surfacing and Pavements: A Guide to Good Practice. London:

OTB Engineering. http://research4cap.org/Library/Cook-etal-Global-2013-LVPGuideline-AFCAP-v130625.pdf. 


\section{Table 2: Sustainability Framework and Issues}

\section{Issue}

Politically and policy supported

Environmentally sustainable

Financially sound

Technically appropriate

Socially acceptable

Institutionally possible

Economically viable

\section{Requirement}

The road program is compatible with identified national policy and is supported in all its aspects at central and local levels.

Road construction, as well as its subsequent use and maintenance, should not cause significant environmental damage and should be compatible with current environmental legislation.

There must be adequate funding or funding mechanisms in place or identified for construction, management, and long-term maintenance of the road and its assets over its proposed design life.

The road design concepts follow national rural transport standards that reflect socioeconomic and transport needs. It should be appropriate for local transport needs, constructible using readily available resources, and maintainable within the expected maintenance regime.

The project is capable of being embraced by and fostering existing social safeguards on issues such as (i) construction standards and measures that improve road safety with followup training especially for vulnerable road users, (ii) resettlement and land acquisition, (iii) community acceptance and participation, (iv) gender equality, and (v) protection of vulnerable groups.

The road project is within the technical capacity of the available road designers and contractors with the necessary resources, knowledge, and experience to carry it forward.

The benefits accruing from the program in terms of socioeconomic developments must be greater than its initial and ongoing costs.

Sources: J. R. Cook, R. C. Petts, and J. Rolt. 2013. Low Volume Rural Road Surfacing and Pavements: A Guide to Good Practice. London: OTB Engineering; Southern African Development Community. 2003. Guideline: Low-Volume Sealed Roads, Gaboroane, Botswana. 


\section{Classification and Appropriate Standards}

An appropriate rural road network management response to LVRR challenges requires a technical framework, which comprises the important elements of (i) classification, (ii) standards, (iii) technical specifications, and (iv) design guidance (Dingen and Cook 2018). Classification provides the country-specific context for broad program design. Standards guide the designs toward the needs of a classification, leading to LVRR technical specifications that define how the roads and associated structures and earthworks must be built to comply with those standards. Finally, there may be an overarching guidance document outlining the application of the standards and specifications, parts of which will be included in any required contract information or terms of reference for works.

The aim of the classification-standards-specification framework is to ensure that roads within a rural road network adhere to key strategic principles and be (i) consistent with any rural development strategy, (ii) compatible with various road environments, (iii) fit-forpurpose, and (iv) sustainable. It is essential to set standards for road provision that match the fit-for-purpose transport requirements with the resources available (Petts, Cook, and Salter 2008).

Furthermore, asset criticality must be integrated into the classification system to identify those LVRRs with a high consequence failure scenario. ${ }^{4}$ Assessing and including asset criticality into the classification system enables better risk management for LVRRs whose failure would have significant impacts beyond the transport system, e.g., an LVRR section that accesses a power plant.
LVRR classification into manageable groups is essential for the division of road networks so that broadly similar good practice design and asset management options can be adopted. It is commonly accepted that there is a strong correlation between traffic level, traffic growth rates, and the administrative function of a road.

Table 3 provides an example of a DMC administrative and function road classification based on several Southeast Asian sources.

However, although traffic levels often increase in line with the administrative classification hierarchy, this is not always true. Traffic levels are likely to differ considerably between different areas and regions of a developing country. Thus, although an administrative classification may benecessary to enable ownership and management responsibilities, it should not be the overarching driver for selecting options for road design. The designation of roads within the LVRR design envelope should be based firmly on the traffic volume and makeup (SEACAP 2008).

Road standards should follow from their classification based upon the road task or purpose to allow for a consistent treatment of all similar roads within the infrastructure system in terms of their design, construction, maintenance requirements, users' expectations, and safety (Petts, Cook, and Salter 2008). LVRR standards should be appropriate for the local environment and accommodate the current road usage and the expected rural developments within a suitable time frame. Stage construction strategies may be appropriate if there is uncertainty regarding future traffic demand and to make the best use of limited resource flows. ${ }^{5}$ 


\section{Table 3: Typical Generic Road Network Classification}

\begin{tabular}{|c|c|c|c|}
\hline Class & \multicolumn{2}{|c|}{ Description and Primary Functions (Tasks) } & Likely Traffic Designation \\
\hline A & \multicolumn{2}{|c|}{ International highway: connects international borders to cities or national road network } & HVT \\
\hline B & \multicolumn{2}{|c|}{ National road: connects towns and cities and to lower-volume road network } & HVT \\
\hline C & \multicolumn{2}{|c|}{$\begin{array}{l}\text { Regional road (feeder road): generally, connects directly to the higher-level road network } \\
\text { or to towns and cities }\end{array}$} & LVRR or possibly HVT \\
\hline D & \multicolumn{2}{|c|}{$\begin{array}{l}\text { District: generally, connects village areas or class E roads to class A rural roads, although } \\
\text { they may connect smaller villages directly to higher-level roads or towns }\end{array}$} & LVRR \\
\hline $\mathrm{E}$ & \multicolumn{2}{|l|}{ Village: village to village or village to agricultural area } & LVRR \\
\hline S & \multicolumn{2}{|c|}{ Special purpose: variable, e.g., quarry road, dam access road, legal logging access } & LVRR, modified as required \\
\hline$u$ & \multicolumn{2}{|c|}{$\begin{array}{l}\text { Unclassified: not with the DMC formal authority but may be providing basic village or } \\
\text { agricultural access }\end{array}$} & Very low traffic \\
\hline \multicolumn{4}{|c|}{$\begin{array}{l}\text { DMC = developing member country, HVT = high-volume transport, LVRR = low-volume rural road. } \\
\text { Note: The table is based on an amalgamation of several Southeast Asian network classifications. } \\
\text { Source: J. R. Cook } 2008\end{array}$} \\
\hline \multicolumn{2}{|c|}{ Climate Impact } & \multirow{2}{*}{\multicolumn{2}{|c|}{$\begin{array}{l}\text { Although climate change impacts are a significant contributor to } \\
\text { LVRR network service level deterioration, it is misleading to design } \\
\text { LVRR program around the assumption that climate impact can be } \\
\text { considered in isolation. Climate change has an undoubted impact on } \\
\text { vulnerable LVRR networks, but it should be recognized at the same } \\
\text { time that LVRR deterioration is a complex process involving several } \\
\text { interacting factors. Therefore, effective climate resilience strategies } \\
\text { should require a holistic approach (Carew-Reid et al. 2011) across a } \\
\text { whole range of issues, as proposed in Figure } 3 \text {. }\end{array}$}} \\
\hline $\begin{array}{l}\text { Rural net } \\
\text { impacts, } \\
\text { standard } \\
\text { axle over } \\
\text { connecti } \\
\text { the pred } \\
\text { events in }\end{array}$ & $\begin{array}{l}\text { are highly vulnerable to current and future climate } \\
\text { g from a low inherent resilience due to lower design } \\
\text { vated by the influences of poor maintenance and } \\
\text {. This low resilience is a significant risk to the overall } \\
\text { the road networks, particularly when combined with } \\
\text { ncreasing occurrence of significant climate shock } \\
\text { ming decades (World Bank 2017). }\end{array}$ & & \\
\hline
\end{tabular}




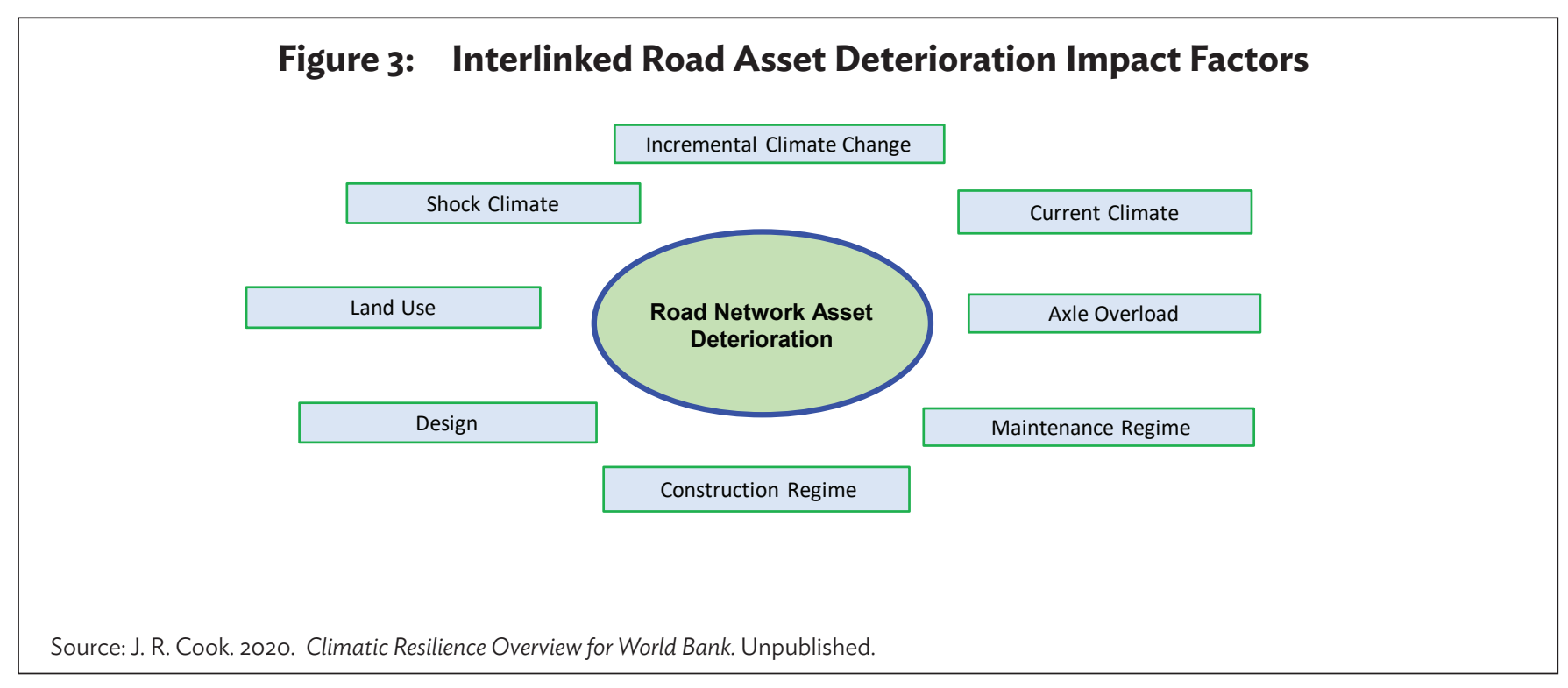

Nevertheless, there is already evidence of climate change impacts on road infrastructure, such as increased rainfall intensity, frequency and severity of flooding events, increased landslide frequency, and damage to roads from excessive heat (ADB 2011). Increases in extreme weather events and unpredictable rainy seasons have created unprecedented backlogs of maintenance and rehabilitation (Verhaeghe et al. 2017 and World Bank 2017). Table 4 presents a summary of climate change impacts on transport infrastructure.

The key principle of applying the logical process of defining the impact, identifying the mitigating options, and determining detailed design and implementation underpin effective and appropriate climate resilience strategies. These strategies are relevant to a range of scenarios, national planning, road network management, road projects, individual roads, and individual road assets. Climate resilience should be holistic and cross-sectoral. Strategies need to be integrated fully within cross-ministry government processes to be effective and sustainable-from government policy down to onthe-ground application. Experience clearly indicates that a holistic cross-sectoral approach should involve route corridors, land use, watersheds, land systems, as well as key nonengineering social, capacity building, and regulatory issues (World Bank 2017).

Figure 4 outlines the options for climate resilience, involving a set of activities that integrate climate change adaptation into transport operations (based on ADB 2011). Activities include screening of project exposure and vulnerability to climate change, technical and economic assessment of climate proofing measures, and monitoring and evaluation (ADB 2014). 


\section{Table 4: Climate Change Impacts on Transport Infrastructure}

\section{Climate}

Increases in very hot days and heat waves

Increases in very hot days and heat waves and decreased precipitation

Increases in temperature in very cold areas

Later onset of seasonal freeze and earlier onset of seasonal thaw

Sea level rise and storm surges

Increase in intense precipitation events

Increases in drought conditions for some regions

Increase of storm intensity

Increase in wind speed
Impacts on Transport Infrastructure

Deterioration of pavement integrity, such as softening, traffic-related rutting, and migration of liquid asphalt due to increase in temperature (sustained air temperature over $32^{\circ} \mathrm{C}$ is identified as a significant threshold) Thermal expansion of bridge expansion joints and paved surfaces

Corrosion of steel reinforcements in concrete structures due to increase in surface salt levels in some locations

Changes in road subsidence and weakening of bridge supports due to thawing of permafrost

Reduced ice loading on structures such as bridges

Deterioration of pavement due to increase in freeze-thaw conditions in some locations

Reduced pavement deterioration from less exposure to freezing, snow, and ice

Damage to highways, roads, underground tunnels, and bridges due to flooding, inundation in coastal areas, and coastal erosion

Damage to infrastructure from land subsidence and landslides

More frequent flooding of underground tunnels and low-lying infrastructure

Erosion of road base and bridge supports

Reduced clearance under bridges

Decreased expected lifetime of highways exposed to storm surges

Damage to roads, subterranean tunnels, and drainage systems due to flooding

Increase in scouring of roads, bridges, and support structures

Damage to road infrastructure due to landslides

Overloading of drainage systems

Deterioration of structural integrity of roads, bridges, and tunnels due to increase in soil moisture levels

Damage to infrastructure due to increased susceptibility to wildfires

Damage to infrastructure from mudslides in areas deforested by wildfires

Damage to road infrastructure and increased probability of infrastructure failures

Increased threat to stability of bridge decks

Increased damage to signs, lighting fixtures, and supports

Suspension bridges, signs, and tall structures at risk from increasing wind speeds

Source: Asian Development Bank. 2011. Guidelines for Climate Proofing Investment in the Transport Sector: Road Infrastructure Projects. Manila. 


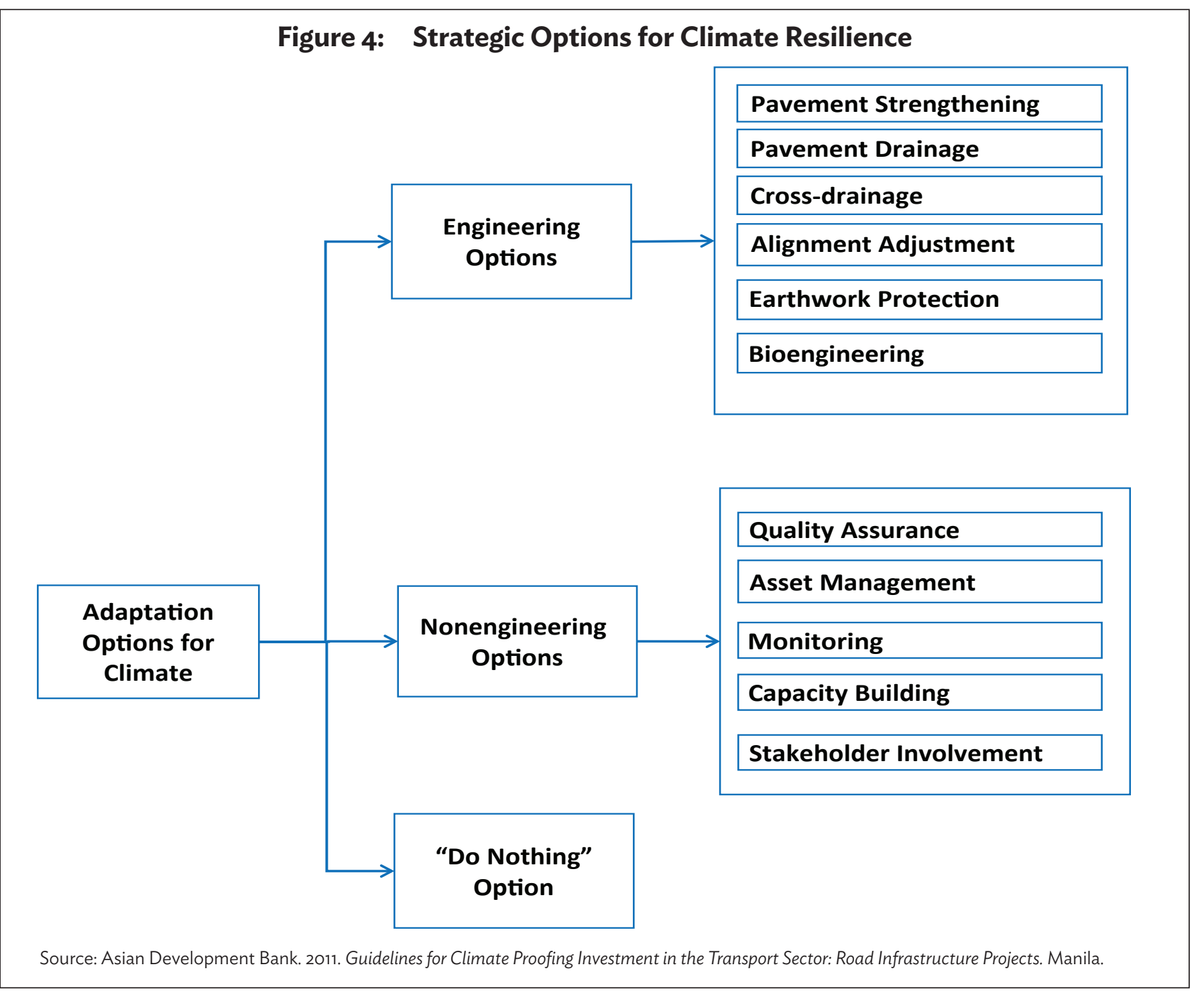


Climate resilience application should facilitate the planning and adoption of both engineering and nonengineering procedures. Engineering options are based on the design and construction of road assets, emphasizing the importance of drainage and drainage structures. Nonengineering options consist of a range of policy, management, and capacity-building improvements. Nonengineering options used to address adaptation for road infrastructure and asset management tend to be more strategic and organizational than engineering options and are generally used in conjunction with engineering options in their application. In most cases, "do nothing" is not equal to the "status quo." Doing nothing to improve climate resilience will, in most scenarios, lead to decreasing levels of service, a decrease in asset value, and a risk to sustainable development.
It is unrealistic to expect a DMC road network to be completely climate resilient, particularly with respect to climate shock impacts. Climate resilience network strategies should consider individual road functions, their socioeconomic and national importance, and their strategic disaster relief efforts. An actual performance level framework must involve discussion with stakeholders, particularly local groups. Possible performance levels are suggested in Table 5. The recent and relevant revised definition for access to be used in the Rural Access Index is that a road that it is likely to be impassable to the prevailing means of rural transport for a total of 7 days or more per year is not regarded as all-season (ReCAP 2019).

\section{Table 5: Possible Performance Levels}

\section{Road Class}

National highway

Provincial road

Urban road

District road

Rural road

Farm access

$<=$ less than.

Source: J. R. Cook. 2020. Climatic Resilience Overview for World Bank. Unpublished.

\section{Impassability Time Following Flood Events: Return Period}

$\begin{array}{cc}\mathbf{5} \text {-Year } & \mathbf{1 0 - Y e a r} \\ 0 & 0 \\ 0 & <6 \text { hours } \\ 0 & <6 \text { hours } \\ <2 \text { hours } & <12 \text { hours } \\ <12 \text { hours } & <2 \text { days } \\ <24 \text { hours } & <5 \text { days }\end{array}$

50-Year

100-Year

$<2$ hours

$<12$ hours

$<24$ hours

$<2$ days

$<24$ hours

$<2$ days

$<2$ days

$<5$ days

$<5$ days

$<7$ days

$<10$ days

$<10$ days 
Recent research explains the rationale and procedures for incorporating hydrological allowances for climate change into detailed engineering design (ADB 2018c). Additional impact channels include water, agriculture, and hydropower (Gebretsadik et al. 2014); and cyclones and storm surge (Neumann et al. 2012). Attention is focused on credible adjustments to extreme rainfall and mean and high-end sea level rise (ADB 2020). It is important to recognize that tropical cyclones in the Asia and Pacific region bring heavy rainfall with high wind speeds, waves, and storm surges. Hence, the design should reflect the possibility of climate-driven changes in multihazards at a site.

Roads make a major imprint on hydrology. They block and guide water, concentrate runoff, interfere with subsurface flows, and change flooding patterns. Ibisch et al. (2016) describe the fragmentation of landscapes that has come with road development. They calculate that, at present, $20 \%$ of the global land surface is within $1 \mathrm{~km}$ of a road. These are also the areas where most people live and where economic activities are concentrated (Green Roads for Water).

Risk-based asset management systems can be considered for key LVRRs that are vulnerable to climate change impacts. These systems provide a basis upon which risk-based asset management decisions can be made (World Bank 2015) and should ideally comprise the following components:

(i) an asset database-for recording data on all asset attributes necessary to operationalize the framework and support wider business needs and objectives;

(ii) a decision support tool-required for risk estimation, risk evaluation, and support for optimized decision-making;

(iii) a geographic information system interface-for interfacing with spatial outputs based on risk information and supporting cross-asset considerations; and (iv) management information-reports that should be produced by the system, be fit-for-purpose, and align with organization business objectives.

\section{Research Uptake and Application}

Since the 1990s the Department for International Development of the United Kingdom (DFID), the World Bank, ADB, and other development partners have supported research on various aspects of rural transport, specifically with the aim of reducing rural poverty and increasing the access to effective transportation services for rural and peri-urban communities in low-income countries. Much of this targeted research has been particularly successful, resulting in innovative and unconventional approaches that can provide highly beneficial and cost-effective solutions for low-volume road access in these countries through, for example, the use of alternative sustainable road surfacings (Visser and Cook 2019, ReCAP 2018).

However, resistance to the implementation of new techniques remains a major challenge to the transfer and application of new knowledge in the transport sector. This is partly due to the inherently conservative nature of the civil engineering profession and the normally lengthy path from research to full implementation, which typically requires a much longer length of time than the timescale of most donor-funded research initiatives (Greening et al. 2010 and Cook et al. 2018). LVRR program decision-makers have a key role to play in accessing and applying research into DMCs, but they are often not reached effectively by researchers with the appropriate evidence or message to encourage and promote action. Much remains to be done in taking up and embedding LVRR research into programs and DMC policy, and continuing to fund research. 
ADB has assisted DMCs in establishing research capacities, such as in India's large-scale Pradhan Mantri Gram Sadak Yojana program (ADB 2012). ADB was actively associated with SEACAP and ReCAP. ${ }^{6}$ DFID-funded programs have delivered and continue to deliver research products of direct relevance to designing LVRR program and the components. ${ }^{7}$

The key lessons from the analysis of research projects are the following:

(i) It is essential to establish a long-term center(s) for conducting research, which also acts as a focal point for knowledge management and transfer.

(ii) Undertaking and disseminating research is not enough. This must be regarded as only an interim step toward uptake and mainstreaming the research results.

(iii) Research, capacity building, and knowledge transfer should not be seen as separate activities.

Activities must be more focused from the very start on the prioritized targets. In moving on from the initial program, stakeholders have to take a much more proactive view of uptake and embedment of the research. Table 6 presents the steps to embed sustainable transport research for its effective application.

\section{Table 6: Steps to Embed Research Capacity}

Step

1. Policy

2. Institutional home

3. Funding

4. Stakeholder support

5. Embedment

\section{Action}

Ensure that the relevant government department, agency, or authority responsible for the overall management of the roads sector is committed to the development or customization of knowledge for improved decision-making. This commitment should be clearly stated in overarching national strategy and policy documents for rural roads and transport.

Ensure that there is a specific section, department, or directorate within the relevant government department responsible for research and knowledge transfer (R\&KT) with clearly defined roles and responsibilities.

Ensure that there is a sustainable source of funding for R\&KT from the national budget. Where road funds have been established, discussions and agreements may be required to allocate funds from this source for R\&KT.

Ensure that there is a formal structure for stakeholder involvement that includes identified key decision-makers.

Develop well-documented and interlinked national policies, strategies, technical guidelines, standards and associated drawings, specifications, and bidding documents for the sector.

ReCAP comprises African Community Access Partnership (AfCAP) and Asian Community Access Partnership (AsCAP).

All SEACAP and ReCAP research reports are freely available on http://research4cap.org/Library.

Source: L. R. Sampson and R. N. Geddes. 2013 Institutionalising Rural Transport Knowledge and Research Capacity in Sub-Saharan Africa. Abstracts of the 32nd Southern African Transport Conference. Pretoria, South Africa: 8-11 July. 
Key topics require further investigation, including appropriate technologies for surfacing and paving, effective maintenance, practical LVRR economic analysis models, and vehicle operating cost (VOC) relationships for local vehicles and road conditions. While there is a relatively large volume of documentation relating to LVRR management theory, there are few examples of where this theory is actually working in practice. Certain projects are cited as successful during or soon after implementation, but not many actually seem to sustain their promise very far into the future (Petts, Cook, and Salter 2008). Having a better understanding of performance over time would be a great help for LVRR management.

\section{Capacity Building}

Capacity building can be an essential element in planning a successful LVRR intervention, and this generally applies to road authorities, contractors, and communities across the LVRR sector. Increasing the capacity of the private sector and the central and local authorities can deliver significant benefits in LVRR areas such as

(i) adoption of new more cost-effective pavement options,

(ii) quality control (contractors) and quality management (local authorities and consultants),

(iii) evidence-based design decisions,

(iv) local materials use,

(v) asset management data acquisition, and

(vi) introduction of innovative contracting mechanisms and various output and performance-based contracting (OPBC) options.
Tailored short courses and training initiatives can address identified knowledge and skill deficiencies as part of LVRR programs. There is also a role for awareness creation initiatives for decision-makers and community representatives. Capacity development is a vital function of the sector that must be adequately and appropriately resourced in budgets (DFID 2013). 


\section{Strategic Decisions in Response to the Road Environment}

A major early decision in many LVRR programs is whether roads should be sealed (paved) or unsealed. Until recently, the commonly applied solution for improving rural access in developing countries was to provide unsealed gravel roads. Superficially, the attractions looked convincing-low initial road cost, all-weather season passage when maintained, and technology so simple that even communities could often be organized to build the roads themselves. However, the shortcomings associated with unsealed gravel roads are increasingly becoming acknowledged, and the decision to employ either sealed or other non-bituminous paved options is becoming more common (Petts, Cook, and Salter 2008).

Research in Southern Africa region and Asia has also shown that sealing can be justified at motor vehicle flows of as low as 70 vehicles per day (VPD) or less. In some extreme combinations of adverse rainfall, gradient, materials, or other factors, a durable pavement will be required for any regular vehicle passage. Furthermore, the range of surface options makes bitumen 'sealing' only one of the many upgrading techniques to be considered. Anticipated traffic generated benefits are also not the only possible justification for improving access to poor rural communities. Research has also highlighted a range of proven alternatives that can provide more sustainable access, each option's suitability depending on the local circumstances and environment (Petts, Cook, and Salter 2008).
The SEACAP 4 project in Viet Nam studied over 700 road sites where gravel surfacing had been used for LVRR projects throughout the country. The study led to recommendations on the restriction of the use of gravel, particularly for locations with adverse factors of material haul distance, traffic, rainfall or flooding, gradient, material quality, and maintenance capability. Figure 5 presents a decision flowchart to determine the appropriateness of gravel as a surfacing option; further guidance on surfacing and paving options is provided in Cook, Petts, and Rolt (2013).

\section{Local Material Use}

The construction material's ability to perform its function in the road is normally assessed by its compliance or noncompliance with material specifications. These specifications are applied to control the impacts of excavation, transportation, processing, compaction and placing, and the in-service impacts of both the traffic and environment depending on the nature and position of the materials in the pavement structure (Cook and Kackada 2008).

The direct application of traditional evaluation criteria and standards when selecting pavement materials for LVRRs is not always appropriate. By necessity, general specifications must cover a very wide range of material types and cater [to] extreme climatic environments. Consequently, they are likely to contain significant in-built factors-of-safety. This means that proven specifications drawn up for specific materials for particular environments need not be so conservative in approach and hence may allow the use of previously non-conforming or marginal materials, if properly processed (Cook and Kackada 2008). 


\section{Figure 5: Decision Flowchart for Natural Gravel as a Rural Road Surface Option}

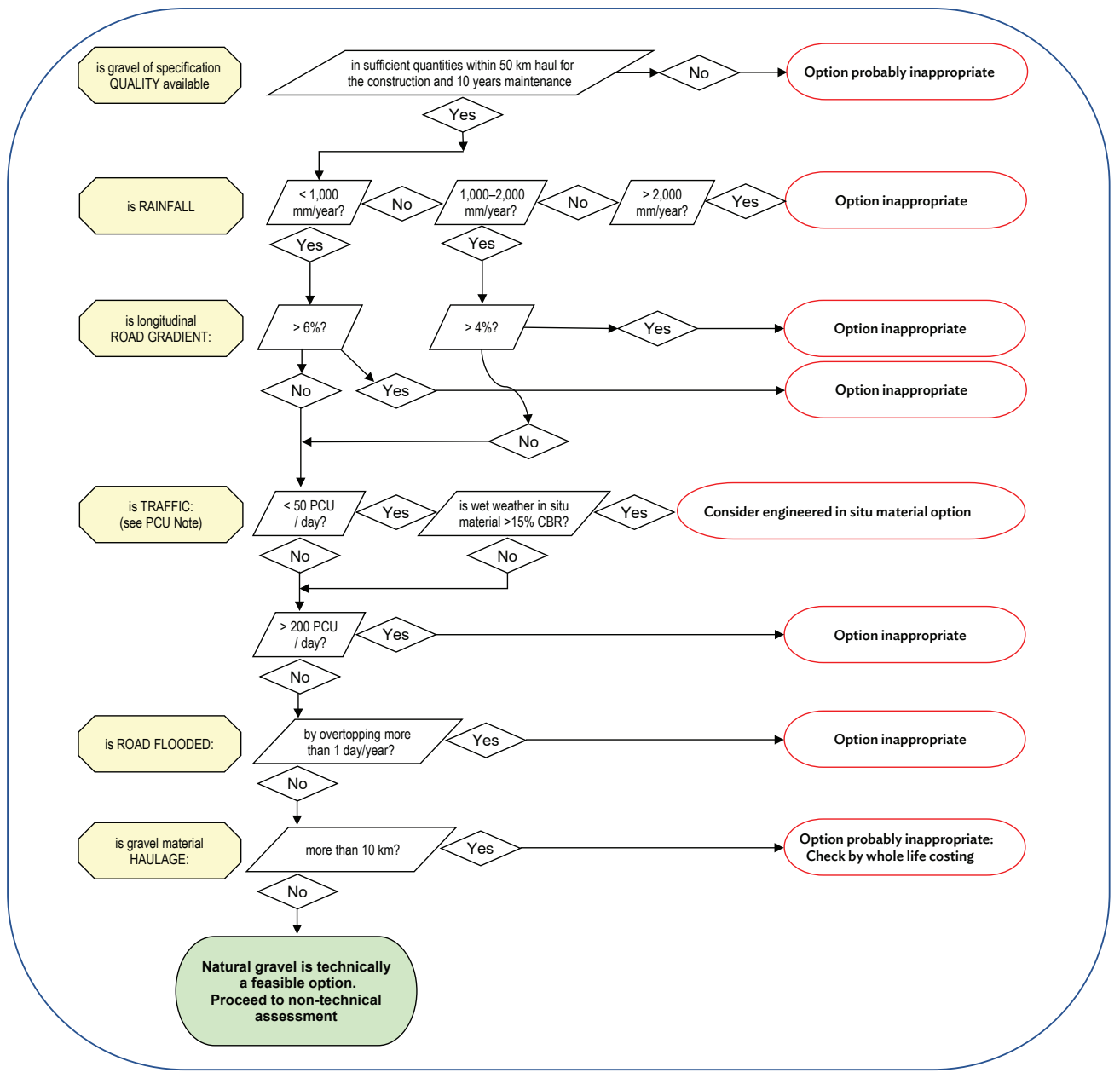

$\mathrm{CBR}=$ California bearing ratio, $\mathrm{km}=$ kilometer $\mathrm{mm}=$ millimeter, $\mathrm{PCU}=$ passenger car unit.

Source: Modified from R. Petts, J. Cook, and D. Salter. 2008. Key Management Issues for Low Volume Rural Roads in Developing Countries. Paper for INCOTALS 2008: South Asia Moves Forward. Colombo. 28 July. 
The expensive materials used in road construction and maintenance are limited and largely nonrenewable resources. Their nature, engineering character, and location are essential aspects of any LVRR assessment. The need to manage scarce financial resources means that the widespread use of local materials is essential for LVRRs. Their appropriateusageisa priorityifreserves arelimitedorofmarginal quality (Cook et al. 2000).

There is a need to ensure that materials used are neither sub-standard nor wastefully above the standards demanded by their engineering task. There is also a growing appreciation that local designs should be adopted to suit the available local materials as much as possible (Cook et al. 2000).

Where genuine material problems or shortages exist, it is the responsibility of the road designers to overcome the issue by (i) adapting the specification and road design to suit local materials (e.g., thickening pavement layers, raising compaction levels, sealing shoulders); and (ii) adapting or modifying the materials to suit a realistic specification (e.g., mechanical or chemical stabilization) (Cook, Petts, and Rolt 2013).

\section{Fit-for-Purpose Design}

The appropriate definition of road categories should be based on local conditions and priorities relating to transport policy, strategy, responsibilities, traffic characteristics, economic and social factors, and not least the financing available. In many DMCs, rural roads are likely to carry substantial flows of intermediate means of transport, such as bicycles and animal-drawn carts, as well as motorcycles and locally made or adapted vehicles. Using appropriate equivalence factors for the various vehicle types will enable calculation of average annual daily traffic for local conditions.
National LVRR design standards should include a wide range of pavement options that are fit-for-purpose with respect to the road tasks and the road environment within which they must perform. Paving options may vary from engineered natural surfaces (ENS) or earth roads to various stone, bituminous, or concrete surfaces. The related spot improvement approach can be considered a legitimate cost-saving extension of an environmentally optimized design that allows upgrade or rehabilitation of problem areas along LVRR alignments, leaving remaining nonproblem sections.

Traditionally, pavement layers (primarily base and sub-base) are designed to withstand the repetitive loading impacts as measured in equivalent standard 8.2-ton axle loads. Standard design charts have been prepared based on numbers of equivalent standard axles (ESAs). Due to the relationship between ESA and road deterioration, very low axle loads (less than 4 tons) have minimal impact on the road in structural terms, compared with environmental physical and climatic surface degradation impacts. An increase in axle load has a deterioration impact to the power of 4.5 , thus high axle loads design parameters such as tire pressure must be considered. Current pavement design charts do not adequately reflect this, and thus LVRRs are frequently overly conservative and costly.

Research studies have led to innovative and unconventional LVRR solutions and highly beneficial and cost-effective approaches, e.g., alternative pavements and surfaces. The key to finding successful solutions is the recognition that conventional assumptions regarding road design criteria need to be challenged.

The progressive changes from earth surfaces to gravel roads to sealed or paved surfacing should be based on traffic loading. The old rule of thumb was: For flows up to 50 (motor) VPD use earth surface, 50-200 VPD use gravel, and above that seal the road (Petts, Cook, and Salter 2008). This approach does not account for 
sustainability and local environmental factors, local materials, haul distances, alignment gradient, and other highly localized issues that are the controls for the relative costs and deterioration of the road and hence must influence the technology choice (Petts, Cook, and Salter 2008).

On any given road alignment there may be some natural soils that are unable to tolerate any sort of traffic, especially when wet. Other in situ soils may be found with strength and performance characteristics that are very easily able to carry quite substantial volumes of traffic in their natural state if adequately shaped and drained. Therefore, the local materials, site characteristics and environment have greater influence on appropriate design, not traffic volumes (Petts, Cook, and Salter 2008).

Often neglected is the ENS or earth road option. This uses the in situ natural material of the road, shaped up to form a camber and drainage provided to ensure that rainwater flows off and away from the road. In the early 1990s, a pilot project in Kenya showed that many sections of LVRR alignment could provide satisfactory access if the earth was shaped up, side drainage and cross drains were provided, and difficult sections such as poor soils or steep gradients were provided with an improved pavement/surface (Petts, Cook, and Salter 2008). Research in Cambodia on a range of road environments indicated that soils with year-round in situ subgrades, with a California bearing ratio of about $15 \%$ or more, are likely to be adequate for low traffic flows and moderate axle loadings (Rolt, Cook, Kackada). In situ, the California bearing ratio can be measured quickly and cheaply using the dynamic cone penetrometer. Spot-improved ENS roads can, in the appropriate circumstance, provide a cost-effective solution for sustainable access.

Table 7 lists the range of proven surfacing and paving options compiled under various research initiatives in Southeast Asia.

\section{Table 7: Surfacing and Paving Options}

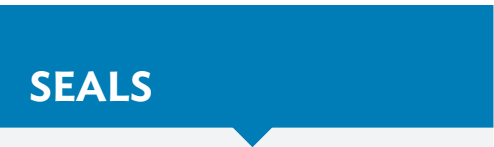

Double emulsion chip seal

Double hot bitumen chip seal

Emulsion sand seal over single chip seal

Single emulsion sand seal

Double emulsion sand seal

Otta seal

\section{UNSEALED SURFACES}

Gravel-wearing course

Water-bound macadam

Hand-packed stone

Engineered natural surface

\section{BLOCK SURFACES}

Stone setts

Cobble stone

Fired clay brick

Concrete brick

Note: Most of the work was done under SEACAP, which was financed by the Department for International Development (DFID) of the United Kingdom.

Source: World Bank. 2014. Improving Vietnam's Sustainability: Key priorities for 2014 and Beyond. Helping Vietnam to Achieve Success as a Middle-Income Country. Washington, DC.

\section{SEALED BASES AND SUB-BASES}

Water-bound macadam

Dry-bound macadam Emulsion stabilized sand

Cement stabilized sand Lime stabilized gravel Lime stabilized clay Armored gravel

Graded crushed stone Natural sand Sand-aggregate mix Natural gravel

\section{CONCRETE}

Steel reinforced Non-reinforced

Cast in situ blocks (Hysen Cells) 
Figure 6 presents a two-stage design approach to identifying the most appropriate surfacing and paving options.

\section{Figure 6: Two-State Identification of the Most Appropriate Surfacing and Paving Options}

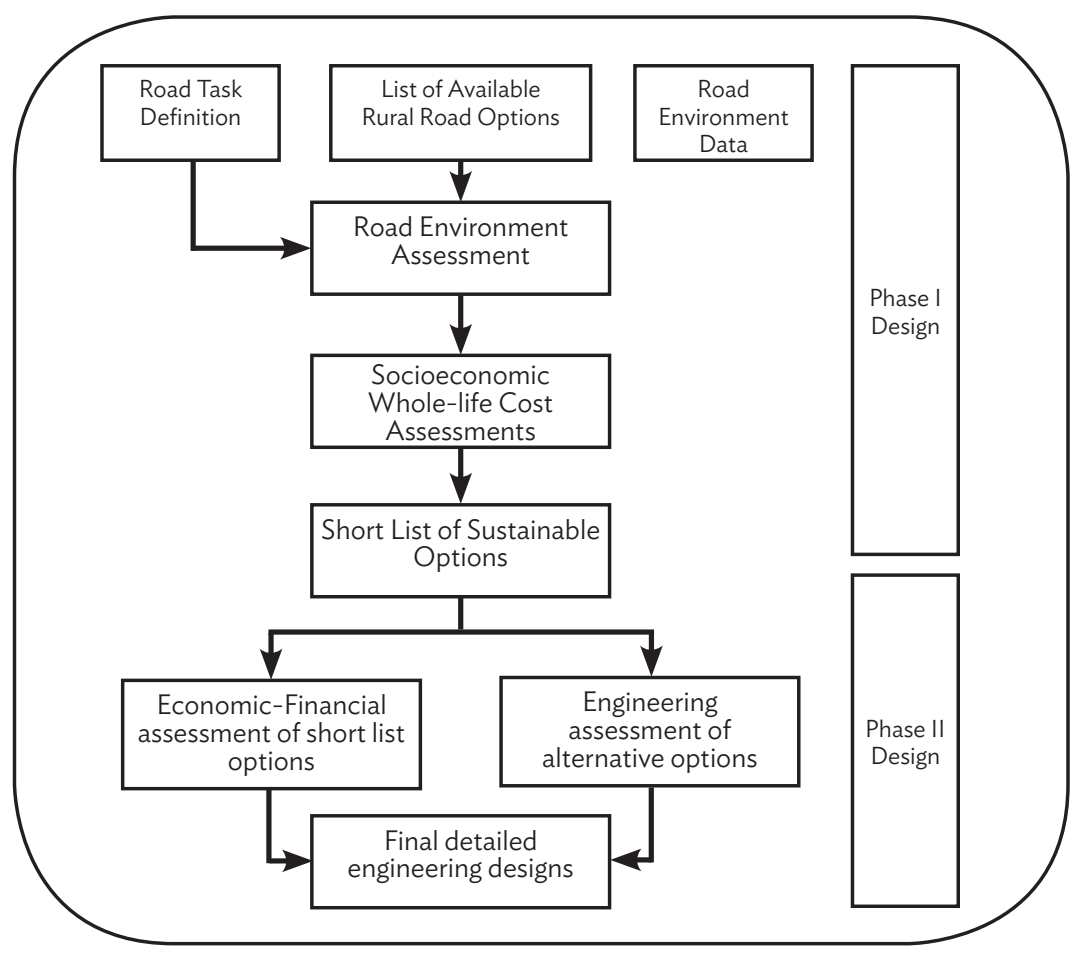

Source: Modified from R. Petts et al. 2006. Rural Road Surfacing Research for Sustainable Access and Poverty Reduction in South East Asia._Ha Noi, Viet Nam: Intech-TRL.

\section{Whole Life Costing}

Whole life costing (WLC) of LVRRs is a preferable approach to comparing only the initial design and construction costs (Australian Road Research Board 1995). The consideration of all present and expected future costs involved with an investment in rural road infrastructure should be an integral part of the design process, especially maintenance aspect assessment (Kackada, Salter, and Cook 2008). There are two possible basic assessments of whole life costs for LVRRs, which may result in somewhat different conclusions depending on the local circumstances: (i) WLC of road assets to the owner and manager, and (ii) WLC of transport to the local economy.

Using WLC for road asset assessments aims to minimize construction and maintenance costs over an appropriate period (normally 10-15years), depending on the road type and location. This assessment is of interest to the road owner and the asset manager. Minimization of WLC for road assets steers the manager toward the best use of available construction and maintenance budgets and best preserves the value of investments in the road infrastructure.

Another application of WLC for road assets is the analysis of various "stage construction" scenarios. In a stage construction strategy, resources are invested in accordance with the development of road use and likely future availability of resources. Improvements and upgrading would follow initial low-cost construction as traffic grows and as additional resources become available. The actual, as opposed to planned, availability and timing of construction and maintenance funding often necessitate compromise solutions and trade-offs.

A WLC for transport assessment has a wider view and includes the impact of the road condition on the local economy. This assessment relies heavily on the estimation of vehicle operating 
costs (VOCs) of the road users and the potential VOC savings from various construction-maintenance strategy options. It may also include other estimations of other economic or socioeconomic impacts (e.g., user time savings and community, environmental, or even local employment generation). This assessment is of more interest to, for example, community representatives, national policy makers, planners, and development agencies (Kackada, Salter, and Cook 2008). Such an assessment aims to minimize the total costs of transport in economic terms over the selected assessment period. This assessment is a complete appraisal of the road condition impact and is preferable. However, currently, there are constraints on the effective application in many LVRR situations.

There are conventional techniques to assess the comparative costs and effectiveness of alternative types of road investments. But they may not be justified in the case of LVRR because they require substantial amounts of data that may not be readily available, and relationships, particularly VOC, require local calibration (Kackada, Salter, and Cook 2008; Archondo-Callao and Faiz 1994). The data would be costly to collect for routine management decisions, would be difficult to analyze with confidence, and may not justify the levels of resourcing required compared to the investment funding available (Petts, Cook, and Salter 2008).

In addition to VOC, the value of time (VOT) to the road user is an important consideration. The difficulty and likely cost of conducting a VOT survey mean that only large projects with significant investment can justify this approach. It is generally accepted that the VOT is positively related to the traveler's income. Users of highvolume roads, such as tolled expressways, can be expected to be on average in a high-income bracket. On the other hand, users of a rural road are likely to have significantly lower income. Nonetheless, the expressway car passenger VOT and vehicle occupancy rate provide a useful reference point for LVRR-assumed VOT as well as vehicle occupancy rates (ADB 2017a).
Any assessment will only be as good as the data and knowledge used in the relationships incorporated in the evaluation. It is evident that for many LVRR situations, the confidence in the cost of data is usually good for the construction inputs. However, the knowledge and confidence are generally poor for both maintenance capacity and cost inputs of various road technology options (and their likelihood of being financed and implemented in a timely manner) and road user VOCs. Similarly, the knowledge of and confidence in the accuracy of other, and often equally important, social and environmental factors are weak. However, as traffic flows on a particular route increase, the potential VOC savings should be more influential in the selection of optimal technology-construction-maintenance strategy (Petts, Cook, and Salter 2008).

Various economic models have been developed to help decision makers assess the balance of road construction and maintenance investments and road user costs, including $\mathrm{HDM}-4$ and the World Bank's Road Economic Decision (RED) model. There are a number of constraints to be considered for the application of these models for the situation of LVRRs in many countries, particularly with regard to the evaluation of VOCs (Petts, Cook, and Salter 2008). VOC per vehicle-kilometer ( $\mathrm{vkm})$ can be assessed from vehicle speed within a speed range of 8-112 km/hr using a tool that estimates of VOC for two basic vehicle types - car and heavy truck (Bailly and Brinckerhoff 1999). The largest component of the estimated VOC is the average fuel cost per vkm. This varies with vehicle speed, while other costs, such as depreciation, lubricating oil, tires, and repair and maintenance, make up an estimated average fixed cost per vkm.

It is possible to derive an approximated VOC for other vehicle types if the relative average fuel consumption of each vehicle is known compared to a car or heavy truck. The United States Federal Highway Administration Highway Capacity Manual (2010) provides a classification of six road levels of service, including an estimate of average traffic speed, given the forecast per lane traffic. 
Combining this classification with the VOC tool (as mentioned by Bailly and Brinckerhoff 1999) makes it possible to forecast average traffic speed, VOC, and vehicle operating time cost. The time cost will require an estimate of VOT per hour. Details of the standard approach for estimating VOT are readily available from several sources (Gwilliam 1997).

For LVRRs without motorized traffic, ADB's Guidelines for the Economic Analysis of Projects suggest a producer surplus approach, which is to estimate net income gains for rural households and firms, where appropriate, created by the improved access allowed by a new project. The method requires assessing the impact of road access on net incomes in the catchment area, controlling for as many other factors as possible that are likely to affect income (ADB 2017a). Table 8 presents the considerations in using common economic models.

\section{Table 8: Considerations in Selecting Economic Analysis Models}

\begin{tabular}{|c|c|}
\hline Item & Consideration \\
\hline 1 & HDM-4 is primarily motor vehicle and roughness driven and is more appropriate for assessing higher category routes. \\
\hline 2 & $\begin{array}{l}\text { VOC relationships for HDM-4 and RED have been developed primarily from experience in Africa and South America, but not yet in } \\
\text { Southeast Asia, where there are climatic, traffic, environmental, operational, and cultural differences. }\end{array}$ \\
\hline 3 & $\begin{array}{l}\text { The models are limited in their ability to deal with the problems of basic access. Many of the key road deterioration and VOC cost } \\
\text { relationships tend to break down for rough earth roads and tracks and very poorly maintained roads. }\end{array}$ \\
\hline 4 & The models do not have VOC relationships for motorcycles and bicycles, which account for most of the traffic on many LVRRs. \\
\hline 5 & There often is a substantial component of pedestrian traffic on LVRRs. \\
\hline 6 & $\begin{array}{l}\text { The commercial vehicles commonly used on LVRRs in many Asian counties are mainly light and slow-moving (often locally made) } \\
\text { trucks and agricultural vehicles, for which VOC-road condition relationships are not well researched. }\end{array}$ \\
\hline 7 & Robust VOC versus road condition knowledge is not available for many LVRR \\
\hline 8 & $\begin{array}{l}\text { The issue of seasonal passability is particularly relevant in roads that become flooded for short or long periods, and gravel roads on weak } \\
\text { subgrades that can become impassable to motorized traffic when severely deteriorated, or routes liable to landslips. }\end{array}$ \\
\hline
\end{tabular}

HDM-4 = Highway Development and Management Model version 4, LVRR = low-volume rural road, RED = Road Economic Decision Model, VOC = vehicle operating cost.

${ }^{a}$ Regional data: Analysis of Vehicle Operating Costs on Rural Roads, Rural Transport Strategy Study, Vietnam, IT Transport, 1999.

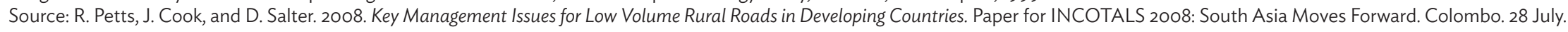


Extreme care is necessary to assess WLCs with due consideration to design, construction, and maintenance costs as well as optimizing the input of local materials, knowledge, and practices. While the incorporation of VOC savings and social benefits is often difficult it is highly desirable and is a priority requiring more research. The deterioration and maintenance requirements of the various surface/ paving options in the range of environments also justifies further research (Petts, Cook, and Salter 2008).

\section{Appropriate Technology}

There are technology choices for most roadworks operations, which can be categorized as labor-based, intermediate equipment, or heavy equipment (Burrow et al. 2016). The choice of technology should be based on some local factors, including availability and cost of labor, size and experience of local contracting organizations, size and technical complexity of the project, and the availability of appropriate standards and specifications. There are significant differences between advanced and emerging economies in terms of the availability and cost of credit, finance, and labor. Different technologies become more or less cost-effective depending on these costs. The private sector and communities should be able to choose technology relating to LVRR construction and maintenance (Hongve et al. 2005, IT Transport 2003).

Labor-based approaches are particularly relevant to countries emerging from conflict or disaster where there is an urgent need to rebuild and get money into effective population in the form of wages. In such situations, the risks are high, which private sector equipment-based firms may be reluctant to face.

Appropriate technology can frequently involve the use of combinations of local labor and low-cost equipment. Trials in Asia and Africa have clearly shown the advantages of utilizing agricultural equipment in both LVRR construction and maintenance (Petts et al. 2006 and Petts and Gongera 2018).

\section{Road Safety}

Road safety is a major risk to communities as traffic increases and speeds go up. Driving skills and safety awareness are weak in many of ADB's DMCs, making any road improvement a risk to the local population. Often, there is little control over vehicular speeds, driver impairment from alcohol, infringement on the road by vendors, limited awareness of risks by pedestrians (both children and adults), and a wide variety and usually poor condition of vehicles. These issues lead to high accident risks, which LVRR programs need to address as an integral part of the implementation plan (ADB 2003).

An LVRR safety program must rely on addressing the "four Es": (i) enforcement, (ii) education, (iii) emergency response, and (iv) engineering. These essential elements have been integrated into the model developed by the International Road Assessment Programme (iRAP) to provide tools and training for road safety. iRAP activities include (i) inspecting high-risk roads and developing star ratings; (ii) producing Safer Roads Investment Plans and risk maps; (iii) providing training, technology, and support that will build and sustain national, regional, and local capability; and (iv) tracking road safety performance so that funding agencies can assess the benefits of their investments. The iRAP Star Rating and Safer Roads Investment Plan model should be used to evaluate and mitigate LVRR risks to road users and those within the road influence (iRAP). 


\section{Quality Management}

Quality management should be an integral part of all LVRR projects. Unfortunately, it is a frequently neglected or poorly addressed issue. ${ }^{8}$ Poor control of construction material quality and construction procedures have a significant negative effect on the performance of LVRR and consequently lead to increased repair and maintenance requirements.

Greater awareness of the importance of quality management is required to be imparted to political, administrative, and engineering personnel through improved awareness creation, training, and project management. Poor quality control by contractors in the first place, compounded by poor quality assurance by supervisors, results in poor return on road asset investment. This issue is critical for all levels of LVRR investment but becomes increasingly significant as the rate of investment increases with the adoption of the more expensive and more durable surfaces allied to climate resilience options. Quality management should comprise a few simple procedures, as set out in Table 9.

In larger LVRR programs, the use of a formal technical audit team should be considered. (Government of Botswana 2001). The purpose of technical audits of road projects is to ensure and enhance the quality of road construction through technical oversight. A technical audit is in addition to the normal quality control and quality assurance procedure that should be undertaken by the contractor and the supervising consultant or engineer. The size and makeup of the team will be a function of project size. The team may comprise just one person for single roads or road assets, and up to three professionals for larger multi-road or asset projects.

\footnotetext{
8 Quality management in this paper is a combination of (i) quality control by a contractor on materials and process and (ii) quality assurance by in-house or appointed supervisors or consultants.
}

The technical audit team is appointed directly by the client (road authority), to whom the team reports directly. To be completely independent, the team should not advise or issue instructions to the contractor or supervising consultant. The structure of a typical technical audit process is outlined in Table 10.

It is not realistic to attempt to force contractors to meet inappropriate road design or unobtainable standards. For overall cost-effectiveness and minimization of environmental impact, LVRR specifications should, where possible, consider the nature of locally available materials. Thus, the use of flexible material specifications that acknowledge local material variations is recommended.

Using more focused specifications ensures that materials comply with the requirements and that the materials approved need to be accompanied by clear guidelines laying out the limits within which the approval is valid.

\section{Road Asset Preservation}

Planning the preservation of new, upgraded, or rehabilitated LVRR assets to achieve the design life should be an essential element of mid- and long-term program planning (PIARC 2013, TRL 2003). In the context of the increasing focus on strengthening the climate resilience of rural road networks, it should be noted that effective routine and periodic maintenance is a key factor in preserving this resilience. Without adequate maintenance, the additional finance invested in climate resilience is likely to be wasted. When any LVRR works are considered, the first assessment should be: What are the expected maintenance arrangements and capabilities, and are they adequate? 


\section{Table 9: Quality Control Procedures in the Rural Road Sector}

\begin{tabular}{|l|l|l|l}
\hline Item & \multicolumn{2}{|c|}{ Quality Control Procedure } & \multicolumn{1}{c}{ Comment } \\
\hline 1 & $\begin{array}{l}\text { Assessment of proposed material } \\
\text { sources combined with control on } \\
\text { as-delivered materials }\end{array}$ & $\begin{array}{l}\text { Quality control research has demonstrated problems with contractors changing materials } \\
\text { between original approvals and actual construction. The principle of testing of construction } \\
\text { materials as delivered and as placed on-site must be adhered to. }\end{array}$ \\
$\begin{array}{ll}\text { Use of simple on-site observational } \\
\text { and testing procedures to control } \\
\text { construction quality } \\
\text { Survey of final as-built quality, including } \\
\text { use of random inspection pitting }\end{array}$ & $\begin{array}{l}\text { The combination of simple standard sheets, on-site measurements, and simple tests such as } \\
\text { DCP and the concrete slump test will assist good quality control, as will annotated and dated } \\
\text { site photographs. }\end{array}$ \\
\hline 3 & $\begin{array}{l}\text { Research has demonstrated the effectiveness of this approach. Superficial drive-over surveys } \\
\text { cannot be considered an alternative if quality assurance is taken seriously as part of the } \\
\text { contractual signing-off procedure. }\end{array}$
\end{tabular}

$D C P=$ dynamic cone penetrometer.

Source: SEACAP. 2008. Low Volume Rural Road Standards and Specifications: Part II: Pavement Options and Technical Specifications.

https://assets.publishing.service.gov.uk/media/57ao8bcaed915d3cfdooof40/Seacap3-LVRR2.pdf.

Experiences in Southeast Asia have shown that the capacity and delivery of maintenance on LVRRs is generally far from adequate. This is due to a complex and interactive range of factors:

(i) insufficient and unstable flow of funds;

(ii) unclear institutional arrangements and responsibilities;

(iii) inadequate appreciation of the importance of maintenance (and economic and social consequences of the lack of maintenance), and lack of an asset management culture;

(iv) insufficient capacity to implement, report, and monitor maintenance activities;

(v) absence of quantified needs, productivity, and cost norms for LVRR maintenance; (vi) technical and management guidance for LVRR maintenance not mainstreamed;

(vii) lack of compiled knowledge and guidance to justify needs for proper maintenance of LVRRs; and

(viii) lack of motivation and cooperation of the principal stakeholders to identify, address, and solve the maintenance challenges.

These factors result in an inadequate provision of essential and priority routine maintenance on most LVRRs, and in a serious inability to make adequate provisions of and arrangements for the expensive, extensive, and vital periodic maintenance re-graveling required of the considerable network of gravel roads. 
Alternative pavements and surfaces to gravel generally have lower maintenance requirements. Routine maintenance includes all off-road surface items such as shoulder repairs, vegetative control, drainage cleaning, and erosion repairs. There will, however, be more drainage cleaning required on unsealed sections of roads as surface materials will be washed into the side drains (TRL-LTEC 2009). Table 11 presents an assessment of expected maintenance activities.

There is an ongoing debate about the pros and cons of force account and the private sector, particularly regarding the implementation of LVRR maintenance. Variations of output and performance-based contracting (OPBC) are increasingly considered an option for the maintenance of LVRRs (Silva and Liautaud 2011). The OPBC option requires careful consideration of the maintenance environment before being adopted, particularly in terms of risk assessment and the capacity and experience of the client and potential contractors. There are possibilities to constructively involve the target beneficiaries - the communities themselves as road maintenance groups - in maintenance delivery (World Bank 2017). The OPBC advantages, disadvantages, and prerequisites for success need to be carefully considered in the local social and operational environment (ADB 2018a).

\section{Table 10: Technical Audit Phases}

\section{.}

Review site and document. Conduct background checks on pricing, work program, personnel, etc.

Assess project management, construction resources, and methodologies.

Assess compliance with specifications, quality and quantity of works, and quality management plans to ensure that it is running smoothly. Review actual cost versus contract budget, and planned progress versus actual progress.

Determine conformance with all aspects of the contract. Actions of the consultant (engineer) and the contractors should be assessed.

Assess and make a comment and recommendations on technical issues raised during the audit process that have not been adequately dealt with.

\section{Aims}

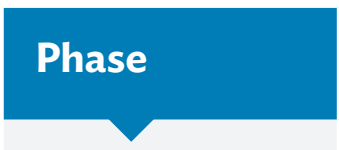

1. Familiarization

2. Initial audit

3. Intermediate audit

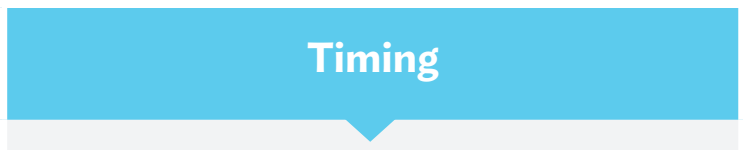

As soon as the contractor is fully mobilized and primary works are underway

Midpoint of the project duration
Prior to contractor mobilization

Note: Small low-volume rural road (LVRR) projects may only require combined phases 1 and 2, and phase 4 .
On completion of all the required construction works and as-built surveys

Only required if recommended by the final audit
Source: ReCAP. 2020. Low Volume Rural Road Design Manual, Ministry of Construction, Republic of the Union of Myanmar Department of Rural Road Development. 


\section{Table 11: Low-Volume Rural Road Maintenance Activity Assessment}

\begin{tabular}{|c|c|c|c|}
\hline $\begin{array}{l}\text { Pavement } \\
\text { Option }\end{array}$ & $\begin{array}{l}\text { Maintenance } \\
\text { Needs Rating }\end{array}$ & $\begin{array}{l}\text { Expected } \\
\text { Routine Maintenance }\end{array}$ & $\begin{array}{l}\text { Expected } \\
\text { Periodic Maintenance }\end{array}$ \\
\hline $\begin{array}{l}\text { Engineered Natural } \\
\text { Surface } \\
\text { (baseline } \\
\text { comparison) }\end{array}$ & High & $\begin{array}{l}\text { BASIC }{ }^{a} \text { plus pothole repairs and camber } \\
\text { reshaping ( } 1-6 \text { times per year). More } \\
\text { frequent on weaker soils and with higher } \\
\text { traffic and rainfall. Camber reshaping } \\
\text { can be achieved manually or by simple } \\
\text { grading equipment. }\end{array}$ & $\begin{array}{l}\text { Raising embankment or camber when worn down, using } \\
\text { local material }\end{array}$ \\
\hline Unsealed Gravel & Very High & $\begin{array}{l}\text { BASIC plus pothole repairs and camber } \\
\text { reshaping ( } 1-3 \text { times per year). Camber } \\
\text { reshaping can be achieved manually or by } \\
\text { simple grading equipment. }\end{array}$ & $\begin{array}{l}\text { High-cost re-graveling to replace material lost due to traffic } \\
\text { and weather. Typically from } 2 \text { to }>5 \text { centimeter of surface } \\
\text { material loss per year depending on the road environment. } \\
\text { The timing of re-graveling is critical; otherwise, the surface } \\
\text { may quickly revert to an earth standard. }\end{array}$ \\
\hline $\begin{array}{l}\text { Sealed Natural } \\
\text { Gravel }\end{array}$ & Moderate & BASIC plus pothole repairs & $\begin{array}{l}\text { Reseal of the surface after maybe 8-12 years (depending on } \\
\text { various road environment factors) }\end{array}$ \\
\hline $\begin{array}{l}\text { Sealed Armored } \\
\text { Gravel }\end{array}$ & Moderate & & \\
\hline Sealed Macadam & Moderate & & \\
\hline $\begin{array}{l}\text { Non-Reinforced } \\
\text { Concrete }\end{array}$ & Low & BASIC only & Crack sealing and joint repairs \\
\hline
\end{tabular}

a. BASIC maintenance refers to non-road surface activities, as described in TRL-LTEC 2009.

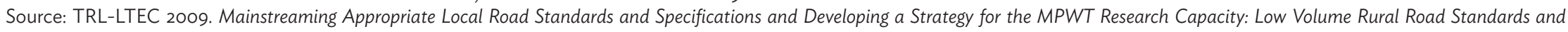
Specifications: Part III: Application of LVRR Standards and Specifications. SEACAP 03. 
In line with ADB's Strategy 2030 of achieving green, sustainable, resilient, and inclusive infrastructure investments, improving LVRR (i) is a precondition necessary for both social and economic development; (ii) is essential for food security by lowering input and output costs, as well as improving market efficiencies; (iii) increases resilience to climate change impacts on agricultural production and options; and (iv) enables not only the movement of food but also the commuting of rural people to employment opportunities in towns and cities, negating the necessity to leave their rural communities. Table 12 shows where and how LVRRs contribute to the operational priorities in the ADB Strategy 2030.

\section{Table 12: Low-Volume Rural Roads in Relation to the ADB Strategy 2030}

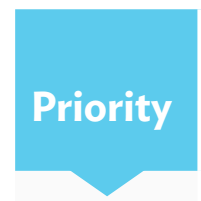

1.

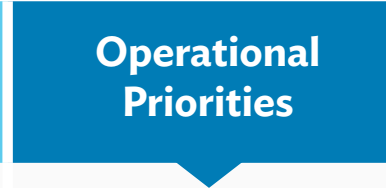

Addressing remaining poverty and reducing inequalities

2.

\section{Accelerating} progress in gender equality

3.

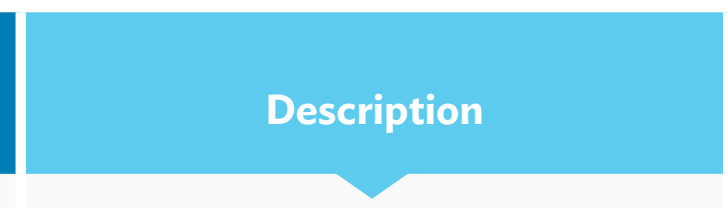

ADB will increase the emphasis on human development and social inclusion to address the non-income dimensions of poverty. It will help facilitate quality job creation, including by small and medium-sized enterprises and inclusive businesses.

ADB will support targeted operations to empower women and girls, gender mainstreaming that directly narrows gender gaps.

ADB will strengthen project planning and design to prevent ecosystem degradation through a variety of approaches, including the use of nature-based solutions, and community-led approaches.

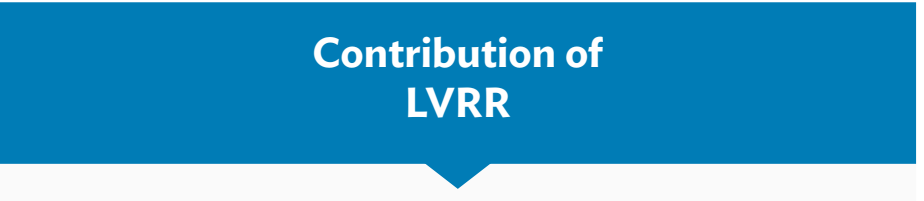

LVRRs increase inclusivity by enabling better access to social and economic opportunities for rural people. Local labor- and resource-based construction and maintenance generates employment and stimulates local enterprises. Rural roads and rural access open up the lowest-income areas.

The capacity of rural women and girls to move safely to meet their economic and social needs is underpinned by good quality LVRR. Rural roads provide local community employment opportunities.

Good quality LVRRs (i) reduce carbon emissions related to transport; (ii) are designed with bioengineering features for infrastructure stability through soil and water conservation; and (iii) optimize the use of local labor materials in construction and maintenance, reducing haulage requirements. 


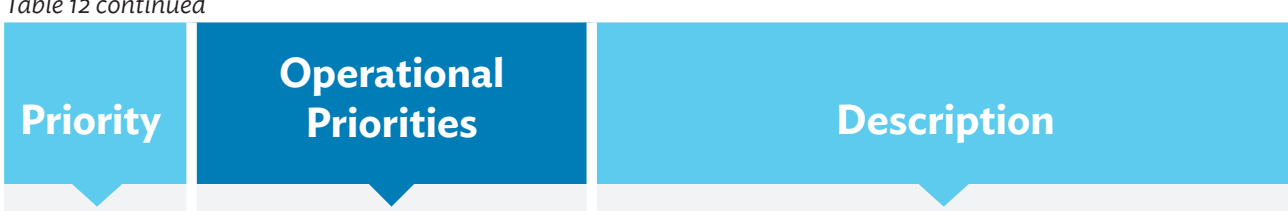

4.

Making cities more livable

5.

Promoting rural development and food security

6.

Fostering regional cooperation and integration
ADB will provide integrated solutions to help build livable cities that are green, competitive, resilient, and inclusive. It will pursue crosscutting projects to promote urban health, urban mobility, gender equality, and environmental sustainability.

ADB will focus on rural roads as part of improving market connectivity and agricultural value chain linkages. ADB will support efforts to improve market connectivity and agricultural value chain linkages. It will help DMCs increase agricultural productivity and food security by boosting farm and nonfarm incomes, promoting the adoption of advanced technologies and climate-smart agricultural practices, and supporting the improvement of natural resource management standards. It will also help DMCs enhance food safety.

In promoting regional public goods, ADB will increase support for enhancing connectivity in the region and the competitiveness of DMCs.
Contribution of

LVRR

Cities require labor that often originates from the rural areas. LVRRs are needed to enable commuting to jobs in the urban areas and to avoid the need for labor to leave their rural communities and the associated social problems that often follow.

LVRRs are essential to achieving rural development and food security. ADB has a renewed focus on rural roads, tracks, and waterways. LVRRs stimulate an expansion of support for logistic services and related facilities.

LVRRs ensure that regional connectivity extends to rural areas to increase market-oriented agricultural production and inclusivity of rural people in the wider socioeconomic developments. 
Asian Development Bank (ADB). 2003. Road Safety Guidelines for the Asian and Pacific Region. Manila.

ADB. 2009. The Economics of Climate Change in Southeast Asia: A Regional Review. Manila.

ADB. 2011. Guidelines for Climate Proofing Investment in the Transport Sector: Road Infrastructure Projects. Manila.

ADB. 2012. Completion Report: Multi Tranche Financing Facility: India: Rural Road Sector II Investment Program (Project 1). Manila.

ADB. 2014. Climate Proofing ADB investment in the Transport Sector: Initial Experience. Manila.

ADB. 2016. Myanmar Transport Sector Policy Note: Rural Roads and Access. Manila.

ADB. 2017a. Guidelines for the Economic Analysis of Projects. Manila.

ADB. 2017b. Viet Nam: Basic Infrastructure for Inclusive Growth in the Northeastern Provinces Sector Project: Ha Giang Subproject 2 Road: Minh Khai, Ha Giang City, to Ngoc Lin Commune and Binh Vang Industrial Zone, Vi Xuyen District.

ADB. 2018a. Guide to Performance-Based Road Maintenance Contracts. Manila.

ADB. 2018b. Strategy 2030: Achieving a Prosperous, Inclusive, Resilient, and Sustainable Asia and the Pacific. Manila.

ADB. 2018c. Adjusting Hydrological Inputs to Road Designs for Climate Change Risk Guidelines to Apply Extreme Value Analysis. ADB Knowledge Product ADB PPTA 8957. Manila.

ADB. 2020. Climate Change Adjustments for Detailed Engineering Design of Roads. Experience from Viet Nam. https://www.adb.org/publications/ climate-change-adjustments-design-roads-viet-nam.
Alkire, S., M. Chatterjee, A. Conconi, S. Seth, and A. Vaz. 2014. Poverty in Rural and Urban Areas: Direct Comparisons Using the Global MPI 2014. University of Oxford, United Kingdom: Oxford Poverty \& Human Development Initiative.

Archondo-Callao, R. S. and A. Faiz. 1994. Estimating Vehicle Operating Costs. World Bank Technical Note. No. 234. Washington, DC: World Bank.

Archondo-Callao, R. S. 1999. Roads Economic Decision Model (RED) for Economic Evaluation of Low Volume Roads. Sub-Saharan Africa Transport Policy Program (SSATP) Technical Note. No. 18. Washington, DC: World Bank.

Australian Road Research Board. 1995. Sealed Local Roads Manual. Section 4: Economic Evaluation. ARRB Transport Research. https://www.arrb.com.au/manual-guides.

Bailly, H. and P. Brinckerhoff. California life-cycle benefit/cost analysis model (Cal-B/C). California Department of Transportation California, 1999.

Burrow, M., R. Petts, M. Snaith, G. Ghataora, and H. Evdorides. 2016. What Is the Evidence Supporting the Technology Selection for Low-Volume, Rural Roads in Low-Income Countries and What Evidence Is There to Support the Sustainability of Different Rural Road Technologies? A Systematic Review. London: EPPI-Centre, University College London.

Carew-Reid, J., T. Ketelsen, A. Kingsborough, and S. Porter. 2011. Climate Change Adaptation and Mitigation (CAM) Methodology Brief. International Centre for Environmental Management. Ha Noi, Viet Nam.

Chinowsky, P. S., A. Schweikert, N. Strzepek, and K. Strzepek. 2012. Road Infrastructure and Climate Change in Vietnam. WIDER Working Paper.

No. 2012/80. Helsinki: United Nations University World Institute for Development Economic Research (UNU-WIDER).

Cook, J.R., C.S. Gourley, E.C. Bishop, and N.E. Elsworth. 2000. Promoting the Use of Marginal Materials. https://www.gov.uk/dfid-research-outputs/ promoting-the-use-of-marginal-materials. 
Cook, J.R. and R.C. Petts. 2005. Rural Road Gravel Assessment Programme. Module 4: Final Report. Intech-TRL.

Cook J.R. and H. Kackada, 2008. Development of Local Resources Based Standards. SEACAP 19: Technical Paper 7. Pilot Road Materials Database. http://research4cap.org/Library/CookKackada-TRL-Cambodia-2008-Tec hnical+Paper7+Materials+Database-SEACAP19-v100203.pdf.

Cook, J.R., R.C. Petts, and J. Rolt. 2013. Low Volume Rural Road Surfacing and Pavements: A Guide to Good Practice. London: OTB Engineering.

Cook, J.R., R. Petts, C. Visser, and A. Yiu. 2017. The Contribution of Rural Transport to Achieve the Sustainable Development Goals.

Cook, J.R, L. Sampson, P. Starkey, and C. Visser. 2016. The Dissemination and Embedment of Applied Rural Transport Research. In Transport and Communications Bulletin for Asia and the Pacific. No 86: Sustainable Rural Access. United Nations Economic and Social Commission for Asia and the Pacific.

Department for International Development (DFID) of the United Kingdom. 2013. Capacity Development: How to Note: Capacity Development.

Dingen, R. and J. Cook. 2018. Review of Low Volume Rural Road Standards and Specifications in Myanmar.

Gebretsadik, Y., K. Strzepek, and C. A. Schlosser 2014. A Hybrid Approach to Incorporating Climate Change and Variability into Climate Scenario for Impact Assessments. World Institute for Development Economics Research, WIDER Working Paper 2014/112, 1-18.

Greening, A.W., P. O'Neill, and J.R. Cook. 2010. The Challenges of Knowledge Transfer Faced by Practitioners in the Transport Sector. Presented at International Conference on Learning Innovation in Science and Technology (ICLIST2010), Pattaya, Thailand.

Gourley, C.S., T. Toole, G. Morosiuk, and J.L. Hine. 2001. Cost Effective Designs for Low Volume Sealed Roads in Tropical and SubTropical Countries. TRL Ltd, United Kingdom. Report ref. S.00240.
Government of Botswana, Ministry of Works, Transport and Communications. 2001. Technical Auditing of Road Projects. Technical Guideline No.7. Gaborone, Botswana.

Government of Myanmar. 2017. National Strategy for Rural Roads and Access.

Green Roads for Water. Introduction.

Gwilliam, K.M. 1997. The Value of Time in Economic Evaluation of Transport Projects. Infrastructure Notes. No. OT-5. Washington, DC: World Bank.

Hine, J., M. Sasidharan, M. Eskandari Torbaghan, M. Burrow, and K. Usman. 2019. Evidence of the Impact of Rural Road Investment on Poverty Reduction and Economic Development. K4D Helpdesk Report. Brighton, UK: Knowledge, Evidence and Learning for Development (K4D), Institute of Development Studies.

International Centre for Environmental Management. 2017. Promoting Climate Resilient Rural Infrastructure in Northern Viet Nam. Technical Report 18: Technical Guidelines for Slope Protection. Ha Noi.

International Labour Organization. 1998. Employment-Intensive Infrastructure Programmes: Labour Policies and Practices. Geneva.

iRAP. Road Safety Toolkit.

Ibisch, P., M. T. Hoffmann, S. Kreft, G. Pe'er, V. Kati, L. Biber-Freudenberger, D. DellaSala, M. Vale, P. Hobson, and N. Selva. 2016. A Global Map of Roadless Areas and Their Conservation Status. Science. 354 (6318), pp. 1423-1427. https://science.sciencemag.org/content/354/6318/1423.

IT Transport. 2003. Community Participation in Road Maintenance: Guidelines for Planners and Engineers. 1st edition.

Kackada, H., D. Salter, and J. Cook. 2008. Whole Life Costs: A Tool for Low Volume Rural Road Managers. Paper for ADB Transport Forum. 9-12 September. 
Karlsson, I. and K. R. de Nowina, eds. 2009. Meeting Global Challenges in Research Cooperation. Uppsala, Sweden: Collegium of Development Studies, Uppsala University.

Larcher, P. R. Petts, and R. Spence. 2010. Small Structures for Rural Roads: A Practical Planning, Design, Construction \& Maintenance Guide.

Lebo, J. and D. Schelling. 2001. Design and Appraisal of Rural Transport Infrastructure: Ensuring Basic Access for Rural Communities. World Bank Technical Paper. No. 496. Washington, DC: World Bank.

Neumann, J. E., K. A. Emanuel, S. Ravela, L. C. Ludwig, and C. Verly. 2015. Risks of Coastal Storm Surge and the Effect of Sea Level Rise in the Red River Delta, Vietnam. Sustainability. 7. pp. 6553-6572. https://www. researchgate.net/publication/277197712_Risks_of_Coastal_Storm_ Surge_and_the_Effect_of_Sea_Level_Rise_in_the_Red_River_Delta_ Vietnam.

Olinto, P., K. Beegle, C. E. Sobrado, and H. Uematsu. 2013. The State of the Poor: Where Are The Poor, Where Is Extreme Poverty Harder to End, and What Is the Current Profile of the World's Poor?

Economic Premise. No. 125. Washington, DC: World Bank.

Permanent International Association of Road Congresses (PIARC). 1999. Road Maintenance Handbook: Practical Guidelines for Rural Road Maintenance. Volumes I-V. https://www.piarc.org/en/order-library/4369en-Road\%20Maintenance\%20Handbook\%20-\%20Practical\%20 Guidelines\%2ofor\%2oRural\%20Road\%20Maintenance.

PIARC. 2013. Best Practices for the Sustainable Maintenance of Rural Roads in Developing Countries. Technical Committee A.4, World Road Association. Paris. https://www.piarc.org/en/order-library/19078-en-Best\%20 practices $\% 2$ foror $\% 20$ the $\% 20$ sustainable $\% 20$ maintenance $\% 200$ f $\% 20$ rural\%2oroads\%2oin\%2odeveloping\%20countries.
Petts, R. 1992. Roads 2000: A Programme for Labour and Tractor Based Maintenance of the Classified Road Network. Paper for RMI road maintenance policy seminar. Nairobi, Kenya.

Petts, R. 2007. LCS Working Paper No 1. Rationale for the Compilation of International Guidelines for Low-Cost Sustainable Road Surfacing, Edition 3.

Petts, R. J. Cook, and D. Salter. 2008. Key Management Issues for Low Volume Rural Roads in Developing Countries. Paper for INCOTALS 2008: South Asia Moves Forward. Colombo. 28 July.

Petts, R. J. Cook, P. G. Tuan, B. T. Dzung, and H. Kackada. 2006. Rural Road Surfacing Research for Sustainable Access and Poverty Reduction in South East Asia. Ha Noi, Viet Nam: Intech-TRL.

Petts, R. and K. Gongera. 2018. Improved Rural Road Network Asset Management through Appropriate Technology. SARF/IRF 2018 Conference on Roads to Social and Economic Growth. Durban, South Africa. 9-11 October.

ReCAP. 2017. Cost/Benefit Analysis of SEACAP Trials in Vietnam http:// research4cap.org/Library/Cooketal-Intech-2017-CBASEACAPIRIM2017-171121.pdf.

ReCAP. 2019. Rural Access Index (RAI) Supplemental Guidelines. Measuring Rural Access Using New Technologies. UKAID-DFID. http://research4cap.org/Library/Workmanetal-TRL-2019-RuralAccessInde xSupplementalGuidelines-ReCAP-GEN2033D-191219-compressed.pdf

ReCAP. 2020. ReCAP, 2020. Low Volume Rural Road Design Manual, Ministry of Construction, Republic of the Union of Myanmar Department of Rural Road Development. UKAID-DFID.

Rolt, J., J.R. Cook, and H. Kackada. Behaviour of Engineered Natural Surfaced Roads: Experimental Evidence in Cambodia. SEACAP 19 Technical Paper No. 2.2. http://research4cap.org/Library/RoltETAL-TRL-Cambodia-2008-Technical+Paper2.2+ENS+Evidence-SEACAP19-v100203.pdf. 
Sampson, L.R. and R.N. Geddes. 2013 Institutionalising Rural Transport Knowledge and Research Capacity in Sub-Saharan Africa. Abstracts of the 32nd Southern African Transport Conference. Pretoria, South Africa. 8-11 July.

SEACAP. 2008. Low Volume Rural Road Standards and Specifications: Part II: Pavement Options and Technical Specifications. https://assets. publishing.service.gov.uk/media/57ao8bcaed915d3cfdooof40/

Seacap3-LVRR2.pdf.

Liautaud, G.L. and M.M. Silva. 2011. Performance-Based Road Rehabilitation and Maintenance Contracts (CREMA) in Argentina: A Review of Fifteen Years of Experience (1996-2010). Transport Papers. No. TP-36. Washington, DC: World Bank.

Southern African Development Community. 2003. Guideline: Low-Volume Sealed Roads. Gaborone, Botswana.

Sustainable Mobility for All. 2019. Global Roadmap of Action Toward Sustainable Mobility: Paper 1: Universal Rural Access. Washington, DC.

TRL-LTEC. 2009. Mainstreaming Appropriate Local Road Standards and Specifications and Developing a Strategy for the MPWT Research Capacity: Low Volume Rural Road Standards and Specifications: Part III: Application of LVRR Standards and Specifications. SEACAP 03 for DFID.

TRL Limited. 2003. Overseas Road Note 20: Management of Rural Road Networks. Crowthorne, Berkshire, United Kingdom.

Verhaeghe, B., P. Paige-Green, A. le Roux, and M. Head. 2017. Climate Adaptation: Risk Management and Resilience Optimisation for Vulnerable Road Access in Africa: Quarterly Progress Report. Thame, Oxford: ReCAP.

Véron-Okamoto, A., and K. Sakamoto. 2014. Toward a Sustainability Appraisal Framework for Transport. ADB Sustainable Development Working Paper Series. No. 31. Manila: Asian Development Bank.

Visser, C. and J. R. Cook. 2019. The Role of Knowledge Management in Ensuring that the Outcomes of Rural Transport Research Are Effectively Applied in Practice. London: Research for Community Access Partnership.
World Bank. 2005. Surfacing Alternatives for Unsealed Rural Roads. Washington, DC.

World Bank. 2014. Improving Vietnam's Sustainability: Key priorities for 2014 and Beyond. Helping Vietnam to Achieve Success as a Middle-Income Country. Washington, DC. http://documents.worldbank.org/curated/ en/752531467986246866/Improving-Vietnam-s-sustainability-keypriorities-for-2014-and-beyond.

World Bank. 2015. Disaster Risk Management in the Transport Sector: A Review of Concepts and International Case Studies. Washington, DC. http://documents.worldbank.org/curated/en/524081468188378328/ pdf/98202-WP-P126896-Box391506B-PUBLIC-DRM-Final.pdf.

World Bank. 2017. Climate Change and Asset Management. Washington, DC. 



\section{Key Management Issues for Low-Volume Rural Roads in Asia and the Pacific}

Rural poverty is directly related to a lack of road access. On average, the rural component of a national road network represents $80 \%$ of the total length, most of which carry low volumes of traffic. These roads are usually neglected and are in chronically poor condition. At the same time low-volume rural roads are essential to reach rural people which are usually the relatively poorest of the population, in no small reason because of their lack of affordable access to social and economic opportunities. This paper describes the key technical and managerial considerations that must be addressed for successful low-volume rural road programs.

\section{About the Asian Development Bank}

ADB is committed to achieving a prosperous, inclusive, resilient, and sustainable Asia and the Pacific, while sustaining its efforts to eradicate extreme poverty. Established in 1966, it is owned by 68 members -49 from the region. Its main instruments for helping its developing member countries

are policy dialogue, loans, equity investments, guarantees, grants, and technical assistance.

\section{$\mathrm{ADB}$}

